\title{
INFLUÊNCIA DE PRESSÕES AMBIENTAIS NA FORMAÇÃO DE REDES MEDIADAS PELOS SISTEMAS DE CONTROLE GERENCIAL EM INCUBADORAS DE EMPRESAS
}

\section{INFLUENCE OF ENVIRONMENTAL PRESSURES ON THE FORMATION OF NETWORKS MEDIATED BY THE MANAGEMENT CONTROL SYSTEMS IN BUSINESS INCUBATORS}

\section{INFLUENCIA DE LAS PRESIONES AMBIENTALES EN LA FORMACIÓN DE REDES MEDIADAS POR SISTEMAS DE CONTROL DE GESTIÓN EN INCUBADORAS DE EMPRESAS}

Recebido em: 14-10-2019

Avaliado em: 18-05-2020

Reformulado em: 16-06-2020

Aceito para publicação em: 06-04-2021

Publicado em: 15-05-2021

Editor Responsável: Franciele Beck
Iago França Lopes ${ }^{1}$

Ilse Maria Beuren²

\section{RESUMO}

Este estudo contribui para uma melhor compreensão da conexão entre a contabilidade gerencial e o seu contexto social, ao oferecer explicações para o fenômeno formação de rede-de-atores em incubadoras de empresas, a partir de elementos contábeis e contingenciais, inscritos nesta investigação nas pressões ambientais. O estudo fundamenta-se na Teoria Ator-Rede (Actor-Network Theory - ANT) e no modelo das alavancas de controle de Simons (1995), para analisar a influência das pressões ambientais na formação de rede-de-atores, mediadas pelos Sistemas de Controle Gerencial (SCG), em incubadoras de empresas. A população da pesquisa compreendeu as incubadoras de empresas das regiões Centro-Oeste, Sudeste e Sul do Brasil. A amostra consistiu em 76 questionários válidos respondidos pelos gestores. Os resultados da Modelagem de Equações Estruturais mostram que as pressões ambientais, entendidas como condições econômicas, influenciam positivamente nos SCG. Ademais, os SCG afetam positivamente elementos estruturais da formação de rede-de-atores. Tem-se ainda o papel mediador dos SCG, na sua dimensão interativa, na relação entre as condições econômicas e o processo de atração de interesses. A ANT explica esse papel mediador do SCG como uma relação sociotécnica, em que os elementos humanos e nãohumanos estão congregados para o alcance de um objetivo. Conclui-se que as pressões ambientais conduzem para a readequação e adoção dos SCG, e que esses estão associados com a formação de redes-de-atores, podendo alterar os atores e a forma da sua relação.

Palavras-chave: Sistemas de Controle Gerencial; Teoria Ator-Rede; Formação de rede-de-atores; Pressões ambientais; Incubadoras de empresas.

\footnotetext{
${ }^{1}$ Doutorando na Universidade Federal do Paraná - UFPR; Mestre em Contabilidade pela Universidade Federal de Santa Catarina - UFSC; E-mail: iagofrancalopes@gmail.com

${ }^{2}$ Doutora em Controladoria e Contabilidade pela FEA/USP; Professora do Programa de Pós-Graduação em Contabilidade da Universidade Federal de Santa Catarina - UFSC; E-mail: ilse.beuren@gmail.com
} 


\section{ABSTRACT}

This study contributes to a better understanding of the connection between management accounting and its social context by offering explanations for the phenomenon of the network of actors in incubator companies, based on accounting elements and contingency inscribed in this investigation in environmental pressures. The study is based on the Actor-Network Theory (ANT) and on the model of control levers by Simons (1995) to analyze the influence of environmental pressures on the formation of actors-networks, mediated by the Management Control Systems (SCG), in business incubators. The research population comprises business incubators from the Midwest, Southeast, and South regions of Brazil. The sample consisted of 76 valid questionnaires answered by managers. The results of Structural Equation Modeling show that environmental pressures understood as economic conditions, positively influence the SCG. Furthermore, the SCG positively affects structural elements of the network of actors. There is also the mediating role of the SCG in its interactive dimension in the relationship between economic conditions, and the process of attracting interest is illustrated. ANT explains this mediating role of the SCG as a sociotechnical relationship in which human and non-human elements are brought together to achieve an objective. We concluded that environmental pressures lead to the readjustment and adoption of the SCG, and these are associated with the formation of actors-networks, changing the actors and the form of their relationship.

Keywords: Management Control Systems; Theory Actor-Network; Network-of-actors formation; Environmental pressures; Business incubators.

\section{RESUMEN}

Este estudio contribuye a una mejor comprensión de la conexión entre la contabilidad de gestión y su contexto social, al ofrecer explicaciones sobre el fenómeno de la red de actores en incubadoras de empresas, basadas en elementos contables y de contingencias, inscritos en esta investigación en presiones ambientales. El estudio se basa en la teoría de la red de actores (ANT) y en el modelo de palancas de control de Simons (1995) para analizar la influencia de las presiones ambientales en la formación de redes de actores, mediado por los Sistemas de Control de Gestión (SCG), en incubadoras de empresas. La población de investigación comprende incubadoras de empresas de las regiones del Medio Oeste, Sudeste y Sur de Brasil. La muestra consistió en 76 cuestionarios válidos respondidos por gestores. Los resultados del modelado de ecuaciones estructurales muestran que las presiones ambientales, entendidas como condiciones económicas, influyen positivamente en el SCG. Además, el SCG afecta positivamente elementos estructurales de la red de actores. También existe el papel mediador del SCG en su dimensión interactiva de la relación entre las condiciones económicas y el proceso de atracción de interés. La ANT explica esta función mediadora del SCG como una relación sociotécnica, en la que elementos humanos y no humanos se unen para lograr un objetivo. Se concluye que las presiones ambientales conducen al reajuste y la adopción del SCG, y que están asociadas con la formación de redes de actores, pudiendo cambiar los actores y la forma de la su relación.

Palabras-clave: Sistemas de control de gestión; Teoría Actor-Red; Formación de redes de actores; Presiones ambientales; Incubadoras de empresas.

\section{INTRODUÇÃO}

Justesen e Mouritsen (2011) apontam que há conexão entre a contabilidade e o contexto social, mas os processos pelos quais ocorrem esses inter-relacionamentos permanecem relativamente obscuros. A conexão está suficientemente estabelecida, mas como tais ligações se desenvolvem na prática tem sido menos examinada. Nesta perspectiva, a literatura contábil vem discutindo a influência das pressões ambientais nos sistemas de controle gerencial (SCG), a qual pode ocorrer de 
forma gradual ou imediata, o que enfatiza a dinamicidade dos sistemas em agir e reagir frente às pressões ambientais (Rautiainen \& Scapens, 2013). A concatenação dessa perspectiva aos acontecimentos no mundo dos negócios respalda-se na conexão entre a contabilidade e o contexto social (Lopes \& Beuren, 2017). A dinâmica das pressões ambientais nos SCG perpassa a compreensão da formação de rede-de-atores, visto que os SCG respondem às contingências ambientais, as quais são capazes de alterar as formas de relacionamento. Essa dinâmica apresenta-se como uma nova maneira de compreender a influência do meio nos SCG e na formação de rede-deatores.

Dessa forma, volta-se ao estudo de Latour (1987), com vistas a uma base teórica pautada na sociologia, a Teoria Ator-Rede (Actor-Network Theory - ANT). O seu conceito seminal de translação/tradução pode oferecer explicações sobre a difusão de inovações, dado a premissa da igualdade de atores humanos e não-humanos em redes e de não ser responsável por estruturas sociais pré-existentes (Windeck, Weber, \& Strauss, 2015). Assim, eleger a ANT como uma lente teórica em estudos contábeis tem como propósito reposicionar ou mesmo fornecer reabilitação para a contabilidade à luz de uma explicação sociológica (Justesen \& Mouritsen, 2011), inserindo-a no contexto social. A mesma tem sido tratada em pesquisas não como atuante no sistema social, mas como receptora das mudanças ambientais.

Reconhecer as pressões ambientais como elementos da estrutura organizacional destaca a relação da organização com o ambiente, o que abre espaço para pesquisas voltadas à organização social e humana e, principalmente, para análises dos efeitos do ambiente sobre a estrutura organizacional (Hannan \& Freeman, 1977). Essa é influenciada, conforme Hall (2004), por: (i) pressões tecnológicas, entendidas como complexidade tecnológica disponível para inovação de novos processos de produção e a dinamicidade e variação tecnológica com que os produtos se tornam obsoletos; (ii) pressões político-legais, vislumbradas como valores e normas que se alteram à medida que os eventos afetam a população envolvida, estratégias governamentais para proteger as atividades industriais e seus investimentos, atitude do governo em relação aos investimentos estrangeiros e tipos de alianças com outros países; e (iii) pressões econômicas, atributo vivenciado pelas empresas com o aumento no nível de pressões, integração global do comércio e diminuição da demanda no mercado.

O domínio dos SCG como meio para mensurar e alocar recursos econômicos é considerado ultrapassado na pesquisa sociológica e ganha força reconhecer como esses sistemas estão relacionados a coalizões políticas, econômicas, sociais e tecnológicas nas organizações (Whittle \& Mueller, 2010). Nesse cenário, a partir da década de 1980, os estudos com explicações sociológicas passam a estar em evidência, já que os modelos racionais, comportamentais, institucionais e cognitivos, pautados em apenas aspectos econômicos, são considerados frágeis para explicar os atributos culturais e as práticas organizacionais rotinizadas nas organizações (Lacruz, Américo, \& Carniel, 2017). Argumenta-se que a transformação e interação dos atores depende das pressões e outras limitações, além de dependências informacionais presentes no processo organizacional. Essas estão continuamente sendo construídas, fazendo e refazendo o social, mas ao mesmo tempo agindo de acordo com ele (Rautiainen \& Scapens, 2013).

A rede-de-atores representa a congregação de elementos humanos e não-humanos que fazem parte da rede a partir de intensidades semelhantes no que concerne às suas respectivas participações para o alcance de objetivos (Latour, 1987). Desse modo, evolui um fluxo de pesquisa empírica voltado ao SCG, nas suas diversas dimensões e características, e à formação de rede-de-atores. Miller (1991) foi um dos primeiros a discutir as questões relacionadas à contabilidade e ANT. Professor da Universidade de Londres, discutia decisões de investimentos a partir de quatro conceitos chaves da ANT (problematizações, programas, tradução e ação à distância). Questionava o papel de inovar dos profissionais de contabilidade gerencial. Com efeito, demonstrou que a inovação ocorre dentro da empresa e que existem mecanismos no escopo contábil que contribuem para tal ação.

Preston, Cooper e Coombs (1992) examinaram a fabricação da caixa-preta formada pelo SCG, que em última instância, é o resultado da integração dos SCG no contexto organizacional. Analisaram 
uma unidade de serviço de saúde do Reino Unido, explorando os processos pelos quais os SCG trazem vantagens econômicas à gestão hospitalar. Posteriormente, no contexto do sistema hospitalar australiano, Chua (1995) encontrou que a ANT é um meio útil para ilustrar a importância da rede de interesses, ao invés da hipótese da racionalidade econômica, na compreensão do processo de mudança da contabilidade.

Pipan e Czarniawska (2010) investigaram a implementação do SCG na administração pública italiana. Argumentam que a ANT fornece uma visão mais complexa e matizada do processo de implementação do SCG. A ANT oferece não só um meio de entender a mudança contábil, mas também muda a natureza e o papel do contador. Nesse sentido, Becker, Jagalla e Skærbæk (2014) ilustraram em seu estudo a transformação da identidade dos contadores no setor público na Alemanha, após a introdução de acréscimos no orçamento baseado no desempenho. Aliyu, Jamil e Mohamed (2014) apresentam proposições de pesquisa em que o SCG é usado como mediador da relação envolvendo o desempenho (financeiro e não-financeiro) dos bancos da Nigéria, pós-crise bancária, e a governança corporativa. O estudo é motivado pela escassez de pesquisas que adotaram o SCG como um mecanismo mediador e direcionado pelo quadro conceitual do SCG proposto por Ferreira e Otley (2009).

Depreende-se que a literatura contábil oferece oportunidades de investigações, visto que: (i) se identificam reflexões acerca dos efeitos da configuração, implementação e uso de SCG (Quattrone \& Hopper, 2005; Hyvönen, Järvinen, \& Pellinen; 2008; Pollack, Costello, \& Sankaran; 2013); (ii) as pesquisas emanam que o SCG se apresenta como um ator não humano, que contribui para o desenvolvimento de estratégias organizacionais, tornando-se um ponto de passagem obrigatório para tal ação (Whittle \& Mueller; 2010), como um atributo que contribui para a criação de uma rede de atores estável, em termos informacionais (Pak, Alwib, \& Ismailb, 2020), e para as ações organizacionais (Zawawi \& Hoque; 2020); (iii) os SCG na tipologia de Simons (1995) mostram-se aptos para receber contribuições sociológicas advindas da ANT (Degenhart \& Beuren, 2019); e (iv) as pesquisas centram-se em ambientes de elevado número de atores com necessidades e interesses informacionais distintos.

Isso denota uma lacuna de pesquisa que carece identificar os elementos que compõem as pressões ambientais e o relacionamento destes com a formação de rede-de-atores, mediadas pelos SCG. Assim, essa investigação pode oferecer explicações mais amplas a respeito das configurações, restrições e efeitos das pressões ambientais na rede-de-atores e como os elementos dos SCG podem alterar as explicações sobre a formação de rede-de-atores em incubadores de empresas. Neste sentido, busca-se responder a seguinte pergunta de pesquisa: Qual a influência das pressões ambientais, mediadas pelos SCG, na formação de rede-de-atores em incubadoras de empresas? As incubadoras de empresas abrigam empreendimentos inseridos em um ambiente que demanda a formação de redesde-atores, especialmente no suporte empreendedor, infraestrutura e capacitação. As incubadoras promovem conexões que favorecem o crescimento de negócios e o acesso ao mercado (Associação Nacional de Entidades Promotoras de Empreendimentos Inovadores - Anprotec, 2016).

Nas pesquisas de Contabilidade Gerencial, Alcouffe, Berland e Levant (2008) destacam que a ANT tem sido utilizada como forma de embasar e sustentar duas questões. A primeira refere-se a quais são os papéis desempenhados pelas inovações da Contabilidade Gerencial dentro das organizações e da sociedade, depois de terem atingido um estado de conjunto de alianças estáveis em torno de um único ator (black boxes) (Latour, 1987). A segunda questão está relacionada à forma como as inovações da Contabilidade Gerencial são produzidas, modificadas e aceitas. De modo geral, estudos em Contabilidade Gerencial usam a ANT para questionar se a tecnologia estabiliza ou estende o controle e a integração.

Esta pesquisa busca fornecer contribuições de cunho teórico, prático e social. No aspecto teórico, esta investigação apresenta contribuições para além dos estudos de Contabilidade Gerencial sob a lente da ANT, como os de Lowe (2001), Alcouffe et al. (2008), Hyvönen et al. (2008), Whittle e Mueller (2010), Pollack et al. (2013), Murro e Beuren (2016), uma vez que integra na rede variáveis 
do sistema social, as pressões ambientais, e elementos da estrutura organizacional, os SCG. Também destaca a necessidade de se pensar a ação humana e não-humana (Lacruz et al., 2017) e o exercício do pensamento em termos difusos e processuais, em vez de tomá-los como fenômenos definidos por uma realidade constituída, racional e objetiva (Cavalcanti \& Alcadipani, 2013).

A proposição dos SCG como mediadores da relação entre pressões ambientais e formação de redes de atores humanos e não humanos está alinhada com a proposta de Latour (1999), de trazer o técnico de volta, a fim de compreender o social. A não separação de elementos humanos e nãohumanos ainda é um desafio para a pesquisa que envolve a ANT (Lee \& Hassard, 1999). Um dos princípios para a aplicação da ANT é o da simetria (Alcadipani \& Hassard, 2010), sob o argumento de que tudo merece uma explicação (Cavalcanti \& Alcadipani, 2013). Neste aspecto, pesquisas prévias revelaram os SCG como mediadores de relações do comportamento de recursos (Beuren \& Vaz, 2016) e de indivíduos no âmbito organizacional (Kleine \& Weißenberger, 2014; Cruz, Frezatti, \& Bido, 2015).

Em termos práticos e sociais, a pesquisa tem a capacidade de sinalizar, para as incubadoras de empresas, a necessidade de considerar os elementos envoltos nas pressões ambientais e nos SCG, para alavancar o desenvolvimento da rede-de-atores. Destaca-se que a formação da rede-de-atores se mostra permeável no que tange à sua transformação, a partir de elementos contábeis e contingenciais, inscritos nesta investigação nas pressões ambientais. Assim, a pesquisa fornece explicações para o fenômeno social denominado formação de rede-de-atores em ambientes inovadores, como das incubadoras e empresas incubadas.

Os resultados desta pesquisa mostram que, das diferentes pressões ambientais envoltas no escopo das incubadoras, apenas as condições econômicas contribuem para explicar a formação de rede-de-atores, mediada pelas variações e alterações no uso dos SCG. As pressões ambientais e as redes estão interligadas e podem mudar ao longo do tempo, da mesma forma que as agências dos atores mudam e vice-versa. Explorar a dinamicidade da agência pode fornecer insights sobre a formação da rede-de-atores a partir das pressões ambientais. Tal fato destaca a importância de investigar a formação da rede-de-atores e de se incorporar a influência do ambiente nos diferentes níveis organizacionais e dentro de campos organizacionais (Rautiainen \& Scapens, 2013).

\section{REFERENCIAL TEÓRICO}

\subsection{Teoria Ator-Rede}

A Teoria Ator-Rede (ANT), fundamentada nas obras de Callon (1986) e Latour (1987, 1999, 2001, 2005), enfoca as relações sociais em redes entre os atores. Esta corrente teórica foi inicialmente desenvolvida no Centre de Sociologie de I'Innovation of the Ecole Nationale Superieure des Mines, entre os anos de 1978 e 1982 (Law, 1992). A ANT caracteriza-se por três aspectos principais: reconhece atores humanos e não-humanos na mesma intensidade, segue os atores na rede e ausência de definição do que é um ator (Latour, 1987, 1999).

A ANT busca explicar o social em termos das ações e interações que ocorrem no campo técnico, econômico, político, ambiental, dentre outros (Tonelli, 2016). Assim, preconiza-se que os acontecimentos, a partir de relações sociotécnicas, representam "participação humana e sua interação com os componentes tecnológicos" (Martins, 2011, p. 80). A ANT fornece uma nova lente pela qual o mundo pode ser visualizado e explorado pelos pesquisadores de Contabilidade Gerencial que desejam conhecer e verificar os efeitos dos processos contábeis de construção em um campo específico (Lukka \& Vinnari, 2014). Na Tabela 1 elucidam-se os componentes principais da ANT.

Uma das constatações da aplicação da ANT é que as entidades são resultados das relações com outras entidades. Discutir conceitos e categorias-chave que envolvem a ANT oportuniza a compreensão decorrente da opção de se romper os limites cognitivos (Tonelli, 2016). Neste cenário, características essenciais e divisionistas se fundem e abandonam o dualismo (Law, 1999). Callon 
Iago F. Lopes, Ilse M. Beuren

(1986) ressalta que a ANT é guiada por três princípios principais: agnosticismo, simetria generalizada e livre associação.

Tabela 1

Elementos da Teoria Ator-Rede

\begin{tabular}{|c|c|}
\hline Elementos & Descrição \\
\hline 1 Ator & $\begin{array}{l}\text { É qualquer entidade capaz de gerar efeito ou deixar rastros, representado por humanos e, } \\
\text { por meio da semiótica, por não-humanos (Latour, 2001). Law (1992, p. 380) sugere que "a } \\
\text { sociedade, as organizações, os agentes e as máquinas são todos efeitos gerados em redes de } \\
\text { diversos materiais". }\end{array}$ \\
\hline 1.1 Ator-rede & $\begin{array}{l}\text { "É uma rede com determinado padrão de relações heterogêneas e distintas, ou um efeito } \\
\text { ocasionado por determinada rede" (Law, 1992, p. 5). }\end{array}$ \\
\hline 1.2 Black box & Conjunto de alianças estáveis em torno de um único actante (Latour, 1988). \\
\hline 1.3 Porta-vozes & $\begin{array}{l}\text { Visto como representante dos actantes, o porta-voz tem a incumbência de expandir os } \\
\text { acontecimentos para incluir atores não humanos nas relações (Latour, 2001). }\end{array}$ \\
\hline 1.4 Ator focal & $\begin{array}{l}\text { Objetiva equilibrar distintos interesses e fazer com que atores se tornem aliados, rumo a um } \\
\text { mesmo alvo, corroborando na construção das relações de determinada situação ou contexto } \\
\text { (Martins, 2011). Para exercer determinado papel, o ator passa a se portar como um } \\
\text { mediador das relações, interferindo, mobilizando e orientando outros atores para uma } \\
\text { configuração adequada das redes (Martins, 2011). }\end{array}$ \\
\hline $\begin{array}{l}\text { 1.5 Ponto de passagem } \\
\text { obrigatória }\end{array}$ & $\begin{array}{l}\text { Refere-se à obrigatoriedade dos atores a passarem por um determinado ponto na rede } \\
\text { (Callon, 1986). }\end{array}$ \\
\hline 2 Translação/ Tradução & $\begin{array}{l}\text { As translações permitem que os actantes se relacionem e se associem entre si, formando } \\
\text { interações fortes ou frágeis, compostas de cadeias discursivas por onde os agentes se } \\
\text { modificam e transladam seus diversos interesses (Latour, 2001) na tentativa de se formar } \\
\text { um todo coeso (Callon \& Latour, 1981). }\end{array}$ \\
\hline 2.1 Problematização & $\begin{array}{l}\text { Refere-se à determinação dos atores das redes e suas identidades, estabelecendo um ponto } \\
\text { de passagem obrigatória na construção das redes (Callon, 1986). }\end{array}$ \\
\hline $\begin{array}{l}2.2 \text { Atração de } \\
\text { interesses }\end{array}$ & $\begin{array}{l}\text { Busca atrair os interesses dos agentes para que se possam criar alianças robustas, por meio } \\
\text { de uma série de artefatos e mecanismos de atratividade (Callon, 1986). }\end{array}$ \\
\hline 2.3 Recrutamento & $\begin{array}{l}\text { Refere-se à atribuição e coordenação de potenciais papéis aos atores elencados na } \\
\text { problematização (Callon, 1986). }\end{array}$ \\
\hline $\begin{array}{l}\text { 2.4 Mobilização dos } \\
\text { aliados }\end{array}$ & $\begin{array}{l}\text { Alguns métodos são utilizados para que os principais interesses dos atores focais não se } \\
\text { desvinculem do propósito inicial e não busquem novas possibilidades para a solução de } \\
\text { uma determinada questão (Callon, 1986). }\end{array}$ \\
\hline 3 Relações híbridas & $\begin{array}{l}\text { Referem-se às alianças entre atores humanos e não humanos em certo contexto (Latour, } \\
\text { 1999). }\end{array}$ \\
\hline 3.1 Ação à distância & $\begin{array}{l}\text { Para retratar um fato, uma realidade ou um acontecimento, os actantes precisam agir à } \\
\text { distância, com o objetivo de formar alianças, causando relações de efeitos entre os } \\
\text { elementos envolvidos (Latour, 1988). }\end{array}$ \\
\hline 3.2 Faz-fazer (fait faire) & Possibilita averiguar as relações de causalidade propiciadas pelos objetos (Latour, 1999). \\
\hline 3.3 Centro de cálculo & $\begin{array}{l}\text { Locais em que se permite verificar quantitativamente informações relevantes relacionadas } \\
\text { às redes, por exemplo, em laboratórios, bancos de dados, centros de pesquisa, organizações, } \\
\text { órgãos governamentais, entre outros (Latour, 2005). }\end{array}$ \\
\hline
\end{tabular}

Fonte: Murro e Beuren (2016, p. 636).

Agnosticismo é a exigência de imparcialidade em relação aos atores envolvidos na rede (Elbaz, 2013). Este princípio reconhece a pluralidade de descrições da natureza, mas não as prioriza ou hierarquiza, há imparcialidade entre os argumentos científicos e tecnológicos. A ANT abstém-se de julgar a maneira como os atores estão analisando a sociedade. Nenhum ponto de vista é privilegiado e nenhuma interpretação é censurada (Callon, 1986).

A simetria generalizada mantém a ideia de equivalência entre atores humanos e não-humanos (Mclean \& Hassard, 2004). Simetria significa que redes são formadas quando atores humanos e nãohumanos têm papéis igualmente importantes (Callon, 1986). O ponto de vista conflitante desses atores heterogêneos pode ser explicado e interpretado por um vocabulário único e imparcial, que trata todos os intervenientes da mesma forma (Callon, 1986). 
Livre associação supõe que os atores heterogêneos podem ser ligados entre si por características comuns, tais como: nacionalidade e aspectos culturais, sociais e naturais (Burgess, Clark, \& Harrison, 2000). Sobre este princípio, Callon (1986) expõe que o pesquisador deve livrarse de todas as distinções, a priori, entre social e natureza, materialidade e sociedade, universidade e empresa. Estas divisões são consideradas conflituosas, pois resultam de análise, em vez de seu ponto de partida.

O debate central da ANT está no escopo do construtivismo social não considerar os elementos não-humanos (Justesen \& Mouritsen, 2011). O construtivismo social, em essência, prioriza o linguístico, que pode ser entendido como parte de narrativas que surgem a partir de construções das atividades linguísticas, intersubjetivas e intertextuais. Não observa, dessa forma, as entidades nãolinguísticas, não-humanas e não-sociais como parte das construções (Tonelli, 2016). Akrich e Latour (1992) apontam que o construtivismo social não considera a ação dos objetos, tendo como premissa que apenas as pessoas são capazes de atuar na construção de fatos. Para Tonelli (2016), há necessidade de mudar esse quadro de referência.

\subsection{Sistemas de Controle Gerencial}

Ferreira e Otley (2009) sinalizam que o estudo dos SCG pode estar consubstanciado em duas dimensões: desenho e uso. O primeiro versa sobre os artefatos e técnicas utilizadas; e o segundo versa sobre as tipologias de uso propostas por Simons (1995; 2000), denominado Levers of Control (LOC). Neste estudo, componentes dos SCG são examinados a partir das dimensões desenvolvidas por Simons (1995; 2000). No entanto, Malmi e Brown (2008) destacam que a falta de clareza na forma como os SCG foram conceituados criou problemas na interpretação dos resultados das pesquisas e na concepção dos SCG. O resultado deste cenário é a diversidade de instrumentos utilizados para capturar o uso dos SCG.

O modelo Levers of Control (LOC's), proposto por Simons (1995), compõe-se de quatro tipos de sistemas: Sistemas de Crenças (Belief Systems); Sistemas de Restrições (Boundary Systems); Sistemas de Controle Diagnóstico (Diagnostic Control Systems); e Sistemas de Controle Interativo (Interactive Control Systems). Henri (2006) expõe que o conceito dessas quatro alavancas se baseia nas chamadas Tensões Dinâmicas. A essência dos SCG é equilibrar as tensões dinâmicas inerentes, por exemplo, a busca por objetivos de longo prazo, sem perder o foco nos objetivos de curto prazo; a necessidade de ter um controle racional dos custos, sem impedir o processo de inovação (Oyadomari, Cardoso, Silva, \& Perez, 2010). Dessa forma, os gestores usam os SCG como forças positivas e negativas para criar tensão dinâmica que contribua para gerir a tensão organizacional inerente.

Na tensão dinâmica, o centro das discussões está na identificação de sistemas que possam equilibrar os objetivos organizacionais (Simons, 2000). Nesta situação, os Sistemas de Crenças e o Sistema Interativo de Controle representam uma força positiva, à medida que geram motivação para o compartilhamento de informações e servem, assim, para expandir as oportunidades de oferta de novos produtos e/ou serviços e de aprendizagem em toda a organização (Henri, 2006). Os Sistemas de Restrições e o Sistema Diagnóstico de Controle representam o papel de feedback tradicional de como o SCG está sendo usado para monitorar e recompensar o cumprimento de metas préestabelecidas (Henri, 2006).

Os sistemas de crenças representam o conjunto explícito dos princípios da cultura corporativa para todos os funcionários da empresa (Simons, 1995). O autor explica que os sistemas de crenças são geralmente amplos e concebidos para comunicar e uniformizar os valores, propósitos e direção para diferentes pessoas que trabalham nos departamentos da organização. Os sistemas de crenças exigem alinhamento entre comportamento organizacional e atitudes da organização, de modo a apresentar coerência com as crenças divulgadas e que possam orientar as decisões nos casos omissos do código de ética (Oyadomari, 2008). Em ambientes dinâmicos, limitações são colocadas aos empregados, para impedi-los de se envolverem em atividades de alto risco, comportamental e organizacional. 
Estas limitações são impostas pelos sistemas de restrições, que agem em oposição aos sistemas de crenças (Widener, 2007). O sistema de restrições é uma alavanca baseada na ideia de que é preciso estabelecer limites, criar e definir novas soluções e métodos para o desenvolvimento das atividades empresariais (Simons, 1995). Oyadomari (2008) afirma que esse sistema auxilia os gestores à medida que delimita o campo de atuação estratégica da empresa e, assim, contribui para mitigar a busca de oportunidades desfocadas. Nos sistemas de crenças e de restrições há tensões dinâmicas, uma vez que ambos têm a intenção de motivar os funcionários a procurar novas oportunidades, mas o sistema de restrições faz isso de uma forma negativa, por meio da restrição do comportamento, enquanto o sistema de crenças faz isso de forma positiva, por meio da inspiração (Widener, 2007).

Os sistemas de controle diagnóstico estão orientados para assegurar a realização das metas previstas, a partir da implementação de estratégias planejadas e para orientar a alta direção quando os resultados não estão alinhados ao estabelecido (Simons, 1995). Têm por função conceder feedback tradicional de como os SCG estão sendo usados para monitorar e recompensar o cumprimento de metas pré-estabelecidas. Seguindo uma noção mecanicista tradicional de controle, o uso diagnóstico fornece motivação e direção para atingir as metas, concentrando-se nos desvios de padrões préestabelecidos de desempenho (Henri, 2006).

Os sistemas de controle interativo têm como propósito controlar as incertezas do escopo organizacional, estimulando o aprendizado e criando um ambiente para potencializar a troca de informações e o desenvolvimento de estratégias emergentes (Simons, 1995). O uso interativo do SCG representa uma força positiva de como o SCG é usado para expandir as oportunidades de procura e de aprendizagem em toda a organização. O uso interativo focaliza a atenção e as forças de diálogo em toda a organização, refletindo ações direcionadas pelos gestores de topo (Henri, 2006).

$\mathrm{O}$ uso conjunto dos SCG de forma diagnóstica e interativa permite gerir as tensões organizacionais inerentes e cria tensão dinâmica. Se adequadamente balanceado, pode contribuir "para o desenvolvimento de competências como empreendedorismo e inovação, gerando oportunidades para aumentar o valor da empresa, sem perder de vista o objetivo de desempenho no longo prazo e flexibilidade" (Oyadomari et al., 2010, p. 24). A tensão dinâmica denota elementos contraditórios, mas inter-relacionados formalmente. A tensão pode ser definida como dois fenômenos em uma relação dinâmica, que envolve tanto a concorrência como a complementaridade (Henri, 2006).

\subsection{Fundamentação das hipóteses}

\subsubsection{Uso dos SCG e pressões ambientais}

O uso dos SCG é influenciado pela configuração do modelo de negócio, induzido pela absorção das pressões ambientais provenientes do contexto social (Lopes \& Beuren, 2018). Dessa forma, as pressões ambientais refletem na maneira como as transformações ocorrem nas organizações (Rautiainen \& Scapens, 2013), e podem exigir a readequação dos SCG (Quattrone \& Hopper, 2001). Nesta perspectiva, as pressões ambientais modificam o desenvolvimento e interferem na configuração e uso dos SCG (Rautiainen \& Scapens, 2013), de modo a absorver as mudanças advindas do ambiente externo e alinhar os processos organizacionais internos.

Emsley (2008) constatou que as pressões ambientais influenciam nos SCG, a partir da alteração eventual do tempo necessário para a conclusão de relatórios. Porém, essa alteração eventual na entrega dos relatórios não estava condicionada apenas ao fator temporal, mas à capacidade dos gestores de fornecerem informações diferentes, não o antigo relatório apresentado mais rapidamente. Nesse ponto, ilustra-se que a configuração dos SCG pode ser alterada, à medida que as organizações estão expostas a contingências ambientais.

Oliveira e Callado (2018) identificaram em 43 organizações listadas na Associação Brasileira de Organizações Não Governamentais (ABONG) que a variável ambiente regulamentar (leis e regulamentos) possui relação direta e significativa com as demonstrações contábeis, variável dos sistemas de controle utilizada, e que o ambiente externo, por meio de pressões, conduz à adoção e 
readequação dos SCG. A nuance percebida é que as pressões ambientais, além de afetarem o aspecto temporal das informações geradas, influenciam na confiabilidade, relevância, precisão e integridade das informações geradas pelos SCG.

Com base nos argumentos teóricos expostos e nos resultados das pesquisas empíricas apontadas, formulou-se a primeira hipótese da pesquisa:

H1: As pressões ambientais influenciam positiva e significativamente no uso dos SCG.

Com a não rejeição da $\mathrm{H}_{1}$, infere-se que a dinâmica dos SCG pode ser vista como o resultado do entrelaçamento técnico e social (Lopes \& Beuren, 2018), de modo a facilitar o planejamento, avaliar o desempenho e o controle na organização, além de ajudar na tomada de decisão e assegurar o uso apropriado de seus recursos (Burns \& Scapens, 2000). Essa dinamicidade impõe linearidade de melhorias racionais ou adaptações funcionais dos SCG para novas demandas em um ambiente de constantes mudança (Justesen \& Mouritsen, 2011).

\subsubsection{SCG e formação de redes de atores humanos e não-humanos}

Os SCG demandam atenção ao projetá-los no ambiente de formação de redes de atores humanos e não-humanos. Os SCG contribuem para a construção da legitimidade organizacional, ao mesmo tempo que potencializam a tomada de decisão, por meio de informações relevantes e com valor preditivo (Abernethy \& Chua, 1996). Portanto, os SCG podem atuar como indutores da formação de rede-de-atores.

No contexto de formação de rede-de-atores, os SCG têm a capacidade de entrelaçar todas as áreas organizacionais e podem trazer mudanças para todo o contexto organizacional (Quattrone \& Hopper, 2001). Nesse sentido, a tensão dinâmica implica em satisfazer todos os atores inscritos na rede-de-atores. O conceito de tensão dinâmica não é necessariamente novo na literatura acadêmica e está relacionado com outros termos, tais como, conflitos, paradoxo, dilema e contraste (Henri, 2006).

Hyvönen et al. (2008) constataram que os SCG possuem a capacidade de moldar a realidade social da organização e sua forma de relacionamento com o ambiente externo. No âmbito das incubadoras de empresas, os SCG têm características que podem influenciar o desenvolvimento de rede-de-atores. Características essas envoltas em: condições políticas, uma vez que são organizações dependentes de políticas desenvolvimentistas; condições legais, por serem organizações dependentes de estruturais legais que fixam a forma de desenvolvimento e operação; e condições econômicas, que regem o escopo organizacional de mudança e continuidade.

Kober, Ng e Paul (2007) evidenciaram que os SCG contribuem para facilitar a mudança na estratégia das organizações. Por outro lado, discute-se que os SCG são o resultado da estratégia organizacional. Hopwood (1987) e Kober et al. (2007) especularam que os SCG poderiam assumir um papel proativo nas organizações, o que resultaria efetivamente no desenvolvimento de rede-deatores. Diante do exposto, considerando a capacidade dos SCG de contribuir para que os objetivos organizacionais sejam alcançados, formulou-se a segunda hipótese da pesquisa:

H2: Os SCG influenciam positiva e significativamente a formação de rede-de-atores humanos e nãohumanos.

A não rejeição da $\mathrm{H}_{2}$ indicará que os SCG são antecedentes da formação da rede-de-atores humanos e não humanos. Dessa forma, os SCG são percebidos como atores importantes em uma teia contínua de manobras adicionais, político-sociais e organizacionais no ambiente das incubadoras de empresas. 


\subsubsection{Papel mediador dos SCG na relação entre pressões ambientais e formação de redes}

Hall (2004) aduz que o ambiente pode ser analisado por meio de condições, que incluem as condições tecnológicas, político-legais e econômicas. As condições tecnológicas representam um ponto central nas discussões a respeito da influência do ambiente nas organizações (Chenhall, 2003). Mendonça, Bulgacov e Costa (2011) observaram que as condições tecnológicas têm capacidade de influenciar de forma distinta na estrutura interna da organização, embasando-se no escopo da sua incerteza e dinamicidade, ratificando a ligação entre ambiente e organização.

As condições político-legais são inerentes ao ambiente organizacional, o que implica atentar aos aspectos legais constituídos nas esferas municipais, estaduais e federais. Reconhece-se, dessa forma, que os dispositivos legais fixam as condições operacionais das organizações (Hall, 2004). As condições legais, na sua maioria, são pautadas pela necessidade ou por interesses. Dessa forma, as leis não são aprovadas sem uma pressão política para a sua promulgação (Hall, 2004).

As condições econômicas também são um pilar das pressões ambientais presentes na formação das organizações e no desenvolvimento de suas relações interorganizacionais. Hall (2004, p. 198) expõe que "as condições econômicas que cercam as organizações melhoram e pioram com a reação das organizações à situação". O autor cita como exemplo a concorrência, como um elemento presente nas condições econômicas que facilmente é visualizada em um mercado em que o sucesso é dependente do mercado competitivo.

Diante dessas condições ambientais, as organizações são obrigadas a reformular suas estratégias de competitividade e permanência no mercado, momento em que o fenômeno da formação de redes-de-atores surge como uma resposta ao ambiente de incerteza e insegurança criado pelas condições ambientais. Nesse aspecto, quatro pontos importantes podem ser destacados. Primeiro, as redes são constituídas ou reconstituídas para projetos específicos, estão em constante fluxo e são formadas a partir da necessidade e/ou interesse de diversos atores com objetivos comuns. Segundo, as redes são reflexos dos relacionamentos contínuos desenvolvidos entre atores humanos e nãohumanos. Terceiro, a ANT fornece um contrapeso para as demais teorias tradicionais, pois atribui poder a atores não-humanos na rede. Quarto, os tradutores são elementos dinâmicos na rede-de-atores e exercem influência direta no desenvolvimento, estabilidade e rompimento da rede-de-atores.

No escopo das pressões ambientais, reconhecidas como contingências com as quais as organizações precisam lidar, e do processo de formação de rede-de-atores, conforme fundamentos da ANT, os SCG, enquanto elementos sociotécnicos (Latour, 1999), têm a capacidade de mudar a redede-atores, suas relações de poder e responsabilidades. Sustenta-se tal inferência, à medida que se observa na literatura resultados que ilustram a capacidade dos SCG responder às questões ambientais (Angonese \& Lavarda, 2017; Lopes \& Beuren, 2018) e, ao mesmo tempo, conduzir relacionamentos interorganizacionais (Silva \& Beuren, 2020).

As pressões ambientais instigam mudanças nos relacionamentos organizacionais, isto é, as pressões ambientais podem estar relacionadas à formação de redes, uma vez que esta tipificação de relacionamento é fruto de incertezas e busca de competitividade (Abernethy \& Chua, 1996, Rautiainen \& Scapens, 2013). Essa proposta encontra sustentação em Latour (1999), que alerta sobre a necessidade de trazer o técnico de volta para compreender o social. A literatura apresenta indícios do papel mediador dos SCG, influenciando o comportamento dos recursos (Beuren \& Vaz, 2016; Angonese \& Lavarda, 2017; Lopes \& Beuren, 2018) e dos sujeitos do escopo organizacional (Kleine \& Weißenberger, 2014; Cruz et al., 2015).

Estudos pregressos têm usado a ANT para questionar se a tecnologia estabiliza ou estende o controle e a integração. Quattrone e Hopper (2005) analisaram como a tecnologia medeia as relações organizacionais e gerenciais à distância, a partir da integração e controle. Dechow e Mouritsen (2005) e Quattrone e Hopper (2005) se reportam ao estudo de Chua (1995) e desafiaram a forma como o conceito de Latour (1987, 1999, 2005) de ação à distância é compreendido e utilizado. Estas aplicações da ANT apresentam evidências de que as relações sociotécnicas demandam mediações, 
visto que a atuação de atores humanos e não-humanos e objetivos comuns precisam ser traçados em termos organizacionais.

Lowe (2001) afirma que a contabilidade pode desempenhar um papel central na criação de condições para que a mudança se torne aceita dentro de uma organização. Assim, alinhado a proposta de que as pressões ambientais atuam como incentivadoras da formação de rede-de-atores, como uma resposta ao cenário de incerteza, insegurança e instabilidade, presume-se que os SCG possam atuar como mediadores desse processo. Tal presunção se baseia em suas características sociotécnicas e sua capacidade de absorver mudanças, bem como fornecer informações de suporte ao desenvolvimento da rede-de-atores (Latour, 1999). Dessa forma, formulou-se a terceira hipótese da pesquisa:

H3: As pressões ambientais influenciam a formação da rede-de-atores, mediadas pelos SCG.

A influência esperada dos SCG como mediadores do processo de formação de rede-de-atores humanos e não humanos associado às pressões ambientais também tem apoio de estudos com os de Bisbe e Otley (2004), Cruz et al. (2015) e Beuren e Vaz (2016), que investigaram os SCG como variável mediadora. Bisbe e Otley (2004) investigaram o papel interveniente dos SCG na relação entre inovação e desempenho organizacional. Cruz et al. (2015) avaliaram o papel mediador dos SCG na relação entre estilos de liderança e inovação tecnológica de empresas. Beuren e Vaz (2016) analisaram o papel mediador dos SCG entre a estratégia ambiental e a performance gerencial.

Na Figura 1 ilustra-se o modelo teórico de pesquisa com as hipóteses formuladas.

\section{Figura 1}

Modelo teórico da pesquisa

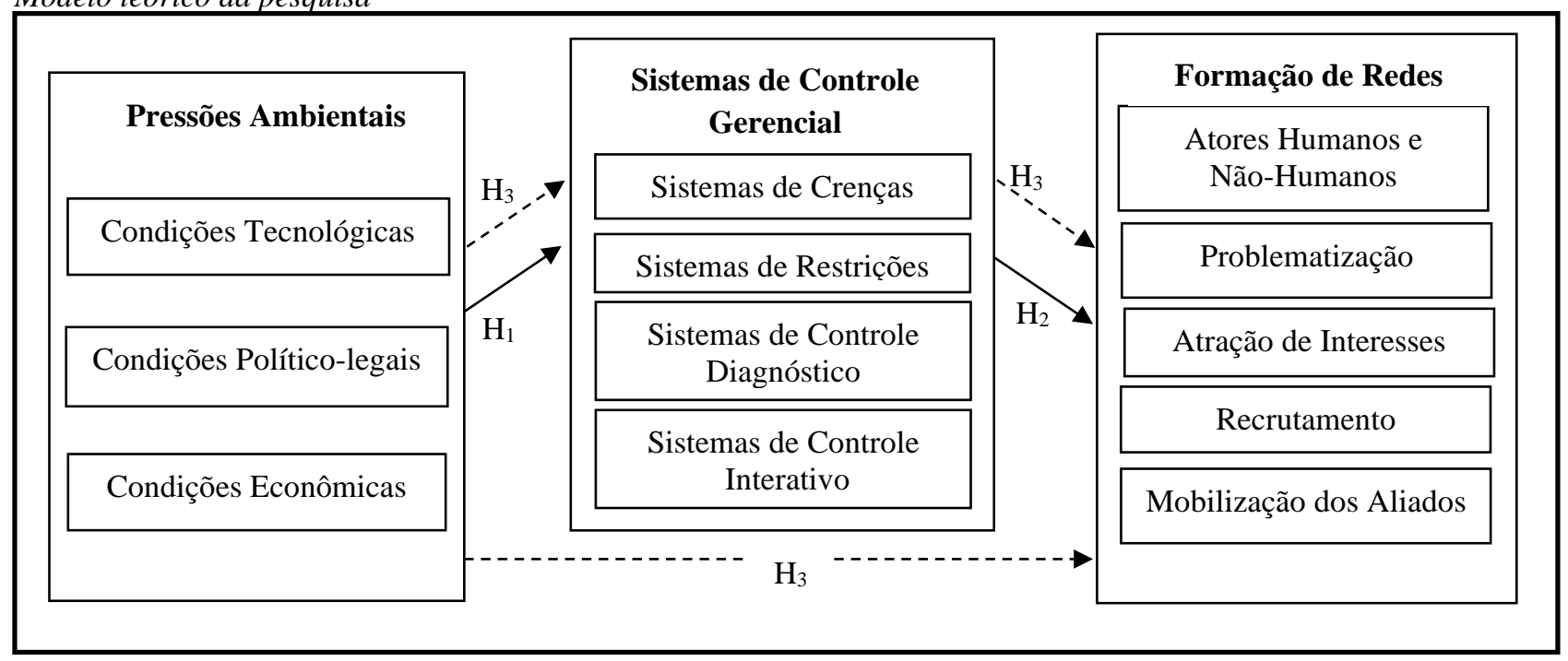

Fonte: Elaboração própria.

Conforme ilustrado na Figura 1, presume-se que os SCG atuam como mediadores da relação entre as pressões ambientais e a formação de redes nas incubadoras de empresas. "O conceito de mediação implica suposição de relacionamentos entre as variáveis envolvidas. A variável mediadora é aquela que, ao estar presente na equação de regressão, diminui a magnitude do relacionamento entre uma variável independente e uma variável dependente" (Abbad \& Torres, 2002, p. 21).

\section{PROCEDIMENTOS METODOLÓGICOS}

\subsection{População e Amostra}

A população desta pesquisa compõe-se das 227 incubadoras de empresas localizadas nas regiões Centro-Oeste, Sudeste e Sul, associadas à Anprotec. A seleção destas incubadoras justifica- 
se pela sua contribuição ao desenvolvimento socioeconômico, à formação do ecossistema empresarial e ao desenvolvimento de empreendedores e empreendimentos mais sólidos e inovadores (Anprotec, 2016). Após contatadas via telefone para obter o endereço de e-mail de colaboradores atuantes no âmbito tático e estratégico, foram enviados convites de participação e o instrumento de pesquisa. Isso resultou em 88 questionários respondidos por gestores de diferentes incubadoras de empresas, sendo um gestor por incubadora, mas apenas 76 mostraram-se completos e válidos. Na Tabela 2 apresentamse dados demográficos dos respondentes da pesquisa.

Tabela 2

Perfil dos respondentes

\begin{tabular}{|c|c|c|c|c|c|}
\hline Gênero & $\overline{\text { FA }}$ & FR (\%) & Cargos Ocupados & FA & FR (\%) \\
\hline Masculino & 40 & 52,63 & Analista de Incubadora & 13 & 17,10 \\
\hline Feminino & 36 & 47,37 & Assistente de Incubadora & 6 & 7,89 \\
\hline Total & 76 & 100,00 & Coordenador de Incubadora & 23 & 30,26 \\
\hline Faixa Etária & FA & FR $(\%)$ & Diretor Executivo & 10 & 13,15 \\
\hline De 18 a 29 anos & 19 & 25,00 & Gerente de Incubadora & 24 & 31,60 \\
\hline De 30 a 39 anos & 24 & 31,58 & Total & 76 & 100,00 \\
\hline De 40 a 49 anos & 20 & 26,32 & Graduação & 8 & 10,52 \\
\hline De 50 a 59 anos & 8 & 10,53 & Especialização & 28 & 36,84 \\
\hline 60 anos ou mais & 5 & 6,58 & Mestrado & 29 & 38,15 \\
\hline \multirow{2}{*}{ Total } & \multirow{2}{*}{76} & \multirow{2}{*}{100,00} & Doutorado & 11 & 14,49 \\
\hline & & & Total & 76 & 100,00 \\
\hline
\end{tabular}

Nota: FA = Frequência Absoluta; FR = Frequência Relativa (\%). Fonte: Dados da pesquisa.

\section{Tabela 3}

Caracterização das incubadoras e das empresas incubadas

\begin{tabular}{|c|c|c|c|c|c|}
\hline \multicolumn{6}{|l|}{ Perfil das incubadoras } \\
\hline Enquadramento da incubadora & FA & FR (\%) & $\mathrm{N}^{\circ}$ de funcionários das incubadoras & FA & $\operatorname{FR}(\%)$ \\
\hline Grande (Maior que 30 empresas incubadas) & 9 & 11,84 & De 1 a 5 funcionários & 53 & 69,74 \\
\hline $\begin{array}{l}\text { Média (maior que } 20 \text { e menor ou igual a } 30 \\
\text { empresas incubadas) }\end{array}$ & 13 & 17,11 & De 6 a 10 funcionários & 17 & 22,37 \\
\hline Micro (menor ou igual a 10 empresas incubadas) & 34 & 44,74 & De 11 a 15 funcionários & 3 & 3,95 \\
\hline $\begin{array}{l}\text { Pequena (maior que } 10 \text { e menor ou igual a } 20 \\
\text { empresas incubadas) }\end{array}$ & 20 & 26,32 & 16 ou mais funcionários & 3 & 3,95 \\
\hline Total & 76 & 100,00 & Total & 76 & $\mathbf{1 0 0 , 0 0}$ \\
\hline \multicolumn{6}{|l|}{ Perfil das empresas incubadas } \\
\hline Enquadramento das incubadas & FA & FR $(\%)$ & Fonte de captação de recursos & FA & FR $(\%)$ \\
\hline As incubadas não possuem faturamento & 7 & 9,21 & Capital Próprio & 23 & 30,00 \\
\hline $\begin{array}{l}\text { Média Empresa (maior que } R \$ 16 \text { milhões e } \\
\text { menor ou igual a } R \$ 90 \text { milhões) }\end{array}$ & 2 & 2,63 & $\begin{array}{l}\text { Fomento (financiamento) captado junto a } \\
\text { instituições públicas/ privadas. }\end{array}$ & 27 & 36,00 \\
\hline Microempresa (menor ou igual a R \$2,5 milhões) & 58 & 76,32 & $\begin{array}{l}\text { Subvenção econômica (incentivo } \\
\text { governamental) captada junto a instituições } \\
\text { públicas. }\end{array}$ & 11 & 14,00 \\
\hline $\begin{array}{l}\text { Pequena Empresa (maior que } R \$ 2,4 \text { milhões e } \\
\text { menor ou igual a } R \$ 16 \text { milhões) }\end{array}$ & 9 & 11,84 & $\begin{array}{l}\text { Fomento (financiamento) e Subvenção } \\
\text { econômica (incentivo governamental) } \\
\text { captada junto a instituições públicas }\end{array}$ & 15 & 20,00 \\
\hline Total & 76 & 100,00 & Total & 76 & $\mathbf{1 0 0 , 0 0}$ \\
\hline Tipologia das incubadoras pesquisadas & & & & FA & FR (\%) \\
\hline Incubadora de Base Tecnológica & & & & 53 & 69,74 \\
\hline Incubadora Mista & & & & 15 & 19,74 \\
\hline Incubadora Social & & & & 3 & 3,95 \\
\hline Incubadora de Setores Tradicionais & & & & 2 & 2,63 \\
\hline Incubadora de Cooperativas & & & & 1 & 1,32 \\
\hline Incubadora de Design & & & & 1 & 1,32 \\
\hline Incubadora de Empresas de Agronegócios & & & & 1 & 1,32 \\
\hline Total & & & & 76 & 100,00 \\
\hline
\end{tabular}

Nota: FA = Frequência Absoluta; FR = Frequência Relativa (\%). Fonte: Dados da pesquisa.

Verifica-se que entre os respondentes das incubadoras de empresas, há prevalência do gênero masculino, faixa etária entre 30 e 39 anos, cargo de coordenador de incubadora e formação acadêmica 
de mestrado. O perfil revela atuação predominante de jovens e com elevado nível de formação. Na Tabela 3 caracterizam-se as incubadoras de empresas.

Nas incubadoras de empresas investigadas predomina o porte micro, na faixa entre 1 a 5 funcionários e com até 10 empresas incubadas. Quanto às empresas incubadas, mostram-se dependentes dessa estrutura para o desenvolvimento dos seus produtos inovadores e prevalecem empresas de base tecnológica, microempresas (com faturamento menor ou igual a $\mathrm{R} \$ 2,5$ milhões) e dependentes exclusivamente de capital próprio.

\subsection{Instrumento de pesquisa}

Para a obtenção de evidências empíricas, recorreu-se a uma survey, realizada a partir de um questionário com três blocos (Apêndice A). O primeiro, relacionado à formação da rede de atores humanos e não-humanos que se formam no ambiente das incubadoras, elaborado com base nos estudos de Raupp e Beuren (2006) e Murro e Beuren (2016). Do estudo de Raupp e Beuren (2006) adaptaram-se assertivas relativas ao contexto de formação de redes em incubadoras de empresas. $\mathrm{O}$ estudo de Murro e Beuren (2016) consubstanciou o uso da ANT no contexto da contabilidade. O respondente foi solicitado a indicar, na escala de intensidade de 7 pontos ( 1 = extremamente baixo; 7 = extremamente alto), o nível de presença dos elementos no processo de formação das redes de atores humanos e não-humanos na incubadora de empresas.

As questões relativas aos SCG foram baseadas nos estudos de Henri (2006), Widener (2007) e Speklé, Van Elten e Widener (2017). Compreendem os Sistemas de Crenças, Sistemas de Restrições, Sistema de Controle Diagnóstico e Sistema de Controle Interativo. As alterações realizadas nas assertivas são de adaptação ao contexto das incubadoras. Para este bloco, o respondente foi solicitado a indicar seu grau de concordância, a partir de uma escala de intensidade de 7 pontos (1 $=$ Discordo totalmente, 7 = Concordo totalmente), quanto à contribuição dos elementos inerentes aos SCG para o desenvolvimento de relacionamentos internos e interorganizacionais.

Por fim, as questões do terceiro bloco referem-se às pressões ambientais, que foram pautadas nos estudos de Badri, Davis e Davis (2000), Hall (2004) e Davila, Foster e Li (2009), compostas neste estudo de condições tecnológicas, político-legais e econômicas. Neste bloco, solicitou-se que o respondente indicasse o nível de presença que cada condição ambiental é incorporada ao processo de formação de redes e na busca de novos parceiros de negócios pela incubadora, a partir de uma escala de intensidade de 7 pontos ( 1 = pouco presente, $7=$ muito presente).

Latour (1999) recomenda que investigações que adotam a ANT como lente teórica sigam os atores na rede. Para Tonelli (2016), o método tem como propósito conhecer as interações e as associações que são construídas em um lócus específico. Melo (2007) descreve que o uso de questionários em pesquisas envolvendo a ANT possibilita seguir os atores em suas redes. Para a aplicação do questionário, utilizou-se a plataforma Survey Monkey, que ficou disponível no período de novembro de 2016 a janeiro de 2017.

\subsection{Tratamento dos dados}

Para análise dos dados utilizou-se a técnica de Modelagem de Equações Estruturais (Structural Equation Modeling - SEM), a qual representa um conjunto de técnicas multivariadas que possibilitam a investigação simultânea de diversos relacionamentos entre variáveis endógenas e exógenas (Henri, 2006). A SEM foi estimada a partir dos Mínimos Quadrados Parciais (Partial Least Squares - PLS) no software SmartPLS3.0. Utiliza-se a SEM para compreender relações mais complexas associadas com as direções de pesquisas atuais nas Ciências Sociais Aplicadas (Hair Jr., Hult, Ringle, \& Sarstedt, 2014). Portanto, o modelo teórico proposto nesta pesquisa possui particularidades exploratórias, tanto para o campo da Contabilidade Gerencial, como para as incubadoras de empresas.

$\mathrm{Na}$ aplicação da técnica SEM, utilizaram-se as recomendações propostas por Hair Jr. et al. (2014). Os autores advogam que para um modelo com quatro caminhos estruturais (maior número de 
setas que chegam a uma variável), com um $\alpha=0,05$ de significância e um $\mathrm{R}^{2}$ mínimo de 0,25 precisase de um tamanho de amostra de 65 respondentes. Ringle, Silva e Bido (2014) apresentam como alternativa de fidelização de constituição de amostra para pesquisas que apliquem a SEM o uso do software $\mathrm{G}^{*}$ Power ${ }^{\circledR}$. Dessa maneira, com um poder (1- $\beta$ err prob) de 0,80 , como recomendado por Cohen (1988) e Hair Jr. et al. (2014), tamanho do efeito $\mathrm{f}^{2}$ mediano $=0,35$ e um $\alpha$ err prob $=0,01$ de significância, a amostra mínima é de 55 questionários. Depreende-se que a amostra da pesquisa com 76 respostas válidas atende ao recomendado e mostra-se adequada para a análise pelo PLS, via bootstrapping. Ringle et al. (2014) descrevem que o bootstrapping é uma técnica de reamostragem utilizada para determinar os coeficientes do modelo estrutural, e que o $\mathrm{R}^{2}$ averigua o poder do modelo com base na amostra e a partir das variáveis endógenas, indicando a qualidade do modelo.

\section{DESCRIÇÃo E ANÁLISE DOS RESULTADOS}

\subsection{Modelo de mensuração}

A Modelagem de Equações Estruturais (PLS-SEM) implica na análise do modelo de mensuração e na avaliação do modelo estrutural (Ringle et al., 2014). Para Hair Jr. et al. (2014), a avaliação do modelo de mensuração inclui a confiabilidade dos indicadores individuais, a confiabilidade composta para avaliar a consistência interna e a variância média extraída (Average Variance Extracted - AVE) para avaliar a validade convergente. Além disso, o critério de FornellLarcker é usado para avaliar a validade discriminante.

O primeiro critério a ser avaliado é a confiabilidade de consistência interna, por meio do alfa de Cronbach e da confiabilidade composta (Ringle et al., 2014). Recomenda-se que o alfa apresente valores superiores a 0,70 , exceto para pesquisas exploratórias, em que pode ser um valor menor (Hair Jr. et al., 2014). A confiabilidade composta é uma medida de consistência interna alternativa ao alfa de Cronbach. A confiabilidade composta varia de 0 a 1 , em que valores maiores indicam maiores níveis de confiabilidade, e é interpretado da mesma forma que o alfa de Cronbach. Valores de confiabilidade composta entre 0,60 a 0,70 são aceitáveis em pesquisas exploratórias (Hair Jr. et al., 2014).

Ambos são usados para avaliar se a amostra está livre de vieses. Dando sequência aos critérios a serem avaliados no modelo de mensuração, o segundo critério diz respeito à validade convergente. É obtida pelas observações das variâncias médias extraídas (Average Variance Extracted - AVE) (Ringle et al., 2014). Para este critério de avaliação do modelo estrutural, nas pesquisas em contabilidade, tem-se comumente utilizado o critério de Fornell-Larcker, cujos valores das AVEs devem ser maiores que 0,50 .

Outro aspecto analisado quanto à adequação do modelo é a validade discriminante. Neste estudo utilizou-se o critério de Fornell e Larcker (1981), que compara as raízes quadradas dos valores das AVEs de cada construto com as correlações entre os construtos. As raízes quadradas das AVEs devem ser maiores que as correlações entre os construtos (Ringle et al., 2014). Na Tabela 4 evidenciam-se os resultados finais do modelo.

Nota-se na Tabela 4, em relação aos índices de adequação do modelo para a confiabilidade de consistência interna, que o alfa de Cronbach não apresenta valores inferiores a 0,70 , corroborando para a aceitação do modelo. A confiabilidade composta do modelo apresentou valores entre 0,70 e 0,90, considerados satisfatórios. Em relação aos índices de adequação do modelo para validade convergente, a AVE não evidenciou valores inferiores a 0,50 , portanto, satisfazem as condições de adequação do modelo de mensuração. Além disso, o valor da validade discriminante de todas as variáveis pelo critério de Fornell e Larcker (1981) é superior aos coeficientes da matriz de correlação da respectiva linha e coluna em que a variável está presente. Tais coeficientes atestam que o modelo apresentado possui validade descriminante e pode-se prosseguir nas análises. 
INFLUÊNCIA DE PRESSÕES AMBIENTAIS NA FORMAÇÃO DE REDES MEDIADAS PELOS SISTEMAS DE CONTROLE GERENCIAL EM INCUBADORAS DE EMPRESAS

Tabela 4

Modelo de mensuração e estatísticas descritivas

\begin{tabular}{ccccccccccccc}
\hline Variáveis & 1 & 2 & 3 & 4 & 5 & 6 & 7 & 8 & 9 & 10 & 11 & 12 \\
\hline 1 & $\mathbf{0 , 7 1 7}$ & & & & & & & & & & & \\
2 & 0,516 & $\mathbf{0 , 7 2 4}$ & & & & & & & & & \\
3 & 0,243 & 0,266 & $\mathbf{0 , 8 9 0}$ & & & & & & & & \\
4 & 0,201 & 0,241 & 0,609 & $\mathbf{0 , 8 8 8}$ & & & & & & & \\
5 & 0,173 & 0,319 & 0,670 & 0,506 & $\mathbf{0 , 7 9 1}$ & & & & & & \\
6 & 0,410 & 0,392 & 0,192 & $-0,012$ & 0,288 & $\mathbf{0 , 7 3 5}$ & & & & & & \\
7 & 0,577 & 0,295 & 0,216 & 0,154 & 0,159 & 0,292 & $\mathbf{0 , 8 2 7}$ & & & & \\
8 & 0,613 & 0,545 & 0,228 & 0,247 & 0,255 & 0,433 & 0,409 & $\mathbf{0 , 7 7 2}$ & & & \\
9 & 0,252 & 0,394 & 0,414 & 0,344 & 0,257 & 0,302 & 0,444 & 0,338 & $\mathbf{0 , 8 7 4}$ & & \\
10 & 0,214 & 0,183 & 0,450 & 0,216 & 0,243 & 0,262 & 0,319 & 0,141 & 0,492 & $\mathbf{0 , 8 2 9}$ & \\
11 & 0,298 & 0,395 & 0,400 & 0,233 & 0,283 & 0,307 & 0,416 & 0,346 & 0,581 & 0,746 & $\mathbf{0 , 8 5 7}$ \\
12 & 0,272 & 0,266 & 0,344 & 0,254 & 0,232 & 0,203 & 0,342 & 0,152 & 0,696 & 0,538 & 0,561 & $\mathbf{0 , 9 1 3}$ \\
\hline Média & 6 & 6 & 5 & 4 & 5 & 6 & 6 & 6 & 6 & 5 & 5 & 5 \\
Desvio padrão & 1 & 1 & 2 & 2 & 2 & 1 & 1 & 1 & 1 & 1 & 1 \\
AVE > 0,50 & 0,514 & 0,524 & 0,792 & 0,788 & 0,625 & 0,54 & 0,685 & 0,596 & 0,763 & 0,687 & 0,734 & 0,834 \\
Conf. Composta $>\mathbf{0 , 7 0}$ & 0,863 & 0,845 & 0,919 & 0,937 & 0,892 & 0,873 & 0,916 & 0,880 & 0,928 & 0,916 & 0,932 & 0,953 \\
Alfa de Cronbach >0,70 & 0,813 & 0,771 & 0,874 & 0,912 & 0,856 & 0,826 & 0,886 & 0,846 & 0,898 & 0,883 & 0,909 & 0,934 \\
\hline
\end{tabular}

Nota: 1 = Atores Humanos e Não Humanos; 2 = Atração de Interesses; 3 = Condições Econômicas; 4 = Condições Político-Legais; 5 = Condições Tecnológicas; 6 = Mobilização dos Aliados; 7 = Problematização; $8=$ Recrutamento; $9=$ Sistemas de Crenças; $10=$ Sistemas de Controle Diagnóstico; $11=$ Sistemas de Controle Interativo; $12=$ Sistemas de Restrições. Fonte: Dados da pesquisa.

\subsection{Modelo estrutural e hipóteses}

Após as avaliações do modelo de mensuração, deve-se avaliar o indicador de ajuste geral do modelo. Segundo Ringle et al. (2014), para tal há três indicadores difundidos na literatura: Coeficiente de Determinação de Pearson $\left(\mathrm{R}^{2}\right)$; Indicador de Stone-Geisser ou Relevância Preditiva (Q2); e Índice de Adequação do Modelo (Goodness of Fit - GoF). Hair Jr. et al. (2014) advertem que o GoF não deve ser utilizado como indicador em pesquisas que utilizam a modelagem PLS-SEM. Assim, nesta pesquisa, optou-se por avaliar o modelo estrutural a partir do Coeficiente de Determinação de Pearson $\left(\mathrm{R}^{2}\right)$ e dos indicadores de Stone-Geisser ou Relevância Preditiva (Q2). Na Tabela 5 apresentam-se os coeficientes de caminho, com base nos dados obtidos pelo Bootstrapping.

Verifica-se na Tabela 5, que a relação direta das variáveis de condições econômicas e SCG foram significativas ao nível de $5 \%$ e $1 \%$. Isso sugere que as condições econômicas se refletem de forma direta nos SCG das incubadoras, reforçando a ideia de que ocorrem adaptações e/ou readequações dos SCG, a partir das condições do ambiente externo. As condições tecnológicas e político-legais não apresentaram influência significativa nos SCG. Com base nesses resultados, a hipótese $\mathrm{H}_{1}$ pode ser aceita parcialmente.

As condições político-legais e tecnológicas não apresentaram relação significativa com os SCG. Portanto, dissonante do estudo de Oliveira e Callado (2018), que constataram influência dos elementos políticos, legais e tecnológicos sobre o controle de ONGs. Já no estudo de Emsley (2008) foi possível identificar parcial alinhamento com os resultados aqui ilustrados, uma vez que em ambos o ambiente externo da organização possui capacidade de influenciar a configuração dos SCG. Especula-se que os diferentes tipos de organizações investigados podem ter influenciado os resultados das pesquisas.

Denota-se que o desenho e o uso dos SCG são submetidos a melhorias racionais ou adaptações funcionais para novas demandas do ambiente econômico. Nessa perspectiva, as condições econômicas difundem-se para manter a sua posição de influência no ambiente das incubadoras de empresas e das incubadas. Ou seja, as condições econômicas apresentam características capazes de moldar os SCG. Os SCG contribuem para a construção da legitimidade organizacional, ao mesmo tempo em que potencializam a tomada de decisão, por meio de informações relevantes e com valor 
preditivo (Abernethy \& Chua, 1996). Portanto, os SCG podem atuar como indutores da formação de redes de atores.

Tabela 5

Coeficientes de caminhos e significância das relações entre SCG e pressões ambientais

\begin{tabular}{clcccc}
\hline Relação estrutural & \multicolumn{1}{c}{ Dimensão } & $\begin{array}{c}\text { Coeficiente } \\
\text { estrutural }\end{array}$ & Erro padrão & Estatística T & $\boldsymbol{P}$ Value \\
\hline \multirow{2}{*}{ Condições Econômicas $\rightarrow$} & CECON $\rightarrow$ SISTC & 0,360 & 0,161 & 2,239 & $\mathbf{0 , 0 2 6}$ \\
Sistemas de Controle Gerencial & CECON $\rightarrow$ SISTDC & 0,559 & 0,146 & 3,838 & $\mathbf{0 , 0 0 0}$ \\
& CECON $\rightarrow$ SISTIC & 0,392 & 0,150 & 2,613 & $\mathbf{0 , 0 0 9}$ \\
& CECON $\rightarrow$ SISTR & 0,306 & 0,158 & 1,939 & $\mathbf{0 , 0 5 3}$ \\
\hline \multirow{2}{*}{ Condições Político-Legais $\rightarrow$ CPL $\rightarrow$ SISTC } & 0,157 & 0,170 & 0,922 & 0,357 \\
Sistemas de Controle Gerencial & CPL $\rightarrow$ SISTDC & $-0,078$ & 0,137 & 0,569 & 0,570 \\
& CPL $\rightarrow$ SISTIC & $-0,022$ & 0,131 & 0,170 & 0,865 \\
& CPL $\rightarrow$ SISTR & 0,073 & 0,164 & 0,444 & 0,657 \\
\hline \multirow{2}{*}{ Condições Tecnológicas $\rightarrow$} & CETC $\rightarrow$ SISTC & $-0,064$ & 0,151 & 0,422 & 0,673 \\
Sistemas de Controle Gerencial & CETC $\rightarrow$ SISTDC & $-0,092$ & 0,152 & 0,607 & 0,544 \\
& CETC $\rightarrow$ SISTIC & 0,032 & 0,153 & 0,209 & 0,834 \\
& CETC $\rightarrow$ SISTR & $-0,009$ & 0,168 & 0,054 & 0,957 \\
\hline
\end{tabular}

Nota: Avaliação do modelo estrutural. $\mathrm{R}^{2}$ : Sistemas de Crenças (SISTC) $=0,187$, Sistemas de Controle Diagnóstico $($ SISTDC $)=0,212$, Sistemas de Controle Interativo $($ SISTIC $)=0,161$, Sistemas de Restrições $($ SISTR $)=0,121$. Relevância Preditiva (Q2): SISTC $=0,123$, SISTDC $=0,130$, SISTIC $=0,096$, SISTR $=0,077$. Fonte: Dados da pesquisa.

Assim, lança-se luz em conhecer a relação entre os SCG e a formação de redes de atores. Na Tabela 6 evidenciam-se os caminhos e coeficientes estruturais da relação entre os SCG e a formação de redes de atores humanos e não-humanos.

Com base nos resultados da Tabela 6, aceita-se parcialmente a hipótese $\mathrm{H}_{2}$. Observa-se relação significativa, ao nível de $10 \%$, entre sistemas de crenças e processo de recrutamento ( $p$-value 0,090); sistemas de controle diagnóstico e processo de atração de interesses ( $p$-value 0,083 ); sistemas de controle interativo e processo de atração de interesses (p-value 0,018); e entre sistemas de controle interativo e processo de recrutamento ( $p$-value 0,041). Com parcimônia, infere-se que os SCG caracterizam-se como antecedentes da formação de redes de atores humanos e não-humanos. Os sistemas de crenças, diagnóstico e interativo destacam-se no processo de formação de redes de atores, indicando que esses sistemas contribuem para as manobras, políticas sociais e organizacionais no ambiente das incubadoras de empresas.

Estes resultados alinham-se aos de Hyvönen et al. (2008), pois os SCG possuem a capacidade de moldar a realidade social da organização. Neste estudo, os SCG possuem a capacidade de moldar o processo de atração de interesses e recrutamento, etapas chave para o desenvolvimento e sucesso de uma rede-de-atores no ambiente das incubadoras. No processo de recrutamento para a formação de redes no ambiente das incubadoras, há influência de elementos técnicos oriundos dos sistemas de crenças das organizações pesquisadas. Assim, o papel que cada ator assume na rede está alinhado com os sistemas de crenças da incubadora de empresas. Tal fato é um alerta para a necessidade de incorporar os elementos dos sistemas de crenças no processo de recrutamento para a formação de redes.

Os sistemas de controle diagnóstico possuem elementos de rigidez quanto ao cumprimento das metas e consumo dos recursos, enquanto os sistemas de controle interativo apresentam elementos mais flexíveis, que se coadunam ao ambiente de inovação. No entanto, como existe uma estrutura legal de dependência de recursos pelas incubadoras, o controle diagnóstico é uma preocupação dos gestores, e está instaurada desde o processo de atração de interesses. Portanto, para formar a rede no ambiente de incubadoras de empresas, essa preocupação em termos de comprometimento com a meta e obtenção de resultados deve ser observada por todos os participantes da rede-de-atores. 
INFLUÊNCIA DE PRESSÕES AMBIENTAIS NA FORMAÇÃO DE REDES MEDIADAS PELOS SISTEMAS DE CONTROLE GERENCIAL EM INCUBADORAS DE EMPRESAS

Tabela 6

Coeficientes de caminhos e significância das relações entre SCG e formação de redes

\begin{tabular}{clcccc}
\hline Relação estrutural & \multicolumn{1}{c}{ Dimensão } & $\begin{array}{c}\text { Coeficiente } \\
\text { estrutural }\end{array}$ & Erro padrão & Estatística T & $\boldsymbol{P}$ Value \\
& SISTC $\rightarrow$ AHNH & 0,047 & 0,298 & 0,159 & 0,874 \\
Sistemas de Crenças $\rightarrow$ & SISTC $\rightarrow$ AINT & 0,299 & 0,217 & 1,376 & 0,170 \\
Formação de Redes & SISTC $\rightarrow$ MOBA & 0,232 & 0,194 & 1,200 & 0,231 \\
& SISTC $\rightarrow$ PROB & 0,310 & 0,203 & 1,527 & 0,127 \\
& SISTC $\rightarrow$ REC & 0,342 & 0,201 & 1,699 & $\mathbf{0 , 0 9 0}$ \\
\hline & SISTDC $\rightarrow$ AHNH & $-0,061$ & 0,229 & 0,269 & 0,788 \\
Sistemas de Controle & SISTDC $\rightarrow$ AINT & $-0,278$ & 0,160 & 1,735 & $\mathbf{0 , 0 8 3}$ \\
Diagnóstico $\rightarrow$ Formação de & SISTDC $\rightarrow$ MOBA & 0,070 & 0,208 & 0,334 & 0,738 \\
Redes & SISTDC $\rightarrow$ PROB & $-0,019$ & 0,173 & 0,112 & 0,911 \\
& SISTDC $\rightarrow$ REC & $-0,255$ & 0,184 & 1,385 & 0,167 \\
\hline \multirow{2}{*}{ Sistemas de Controle } & SISTIC $\rightarrow$ AHNH & 0,239 & 0,247 & 0,968 & 0,333 \\
Interativo $\rightarrow$ Formação de & SISTIC $\rightarrow$ AINT & 0,456 & 0,193 & 2,366 & $\mathbf{0 , 0 1 8}$ \\
Redes & SISTIC $\rightarrow$ MOBA & 0,172 & 0,236 & 0,729 & 0,466 \\
& SISTIC $\rightarrow$ PROB & 0,253 & 0,169 & 1,497 & 0,135 \\
SISTIC $\rightarrow$ REC & 0,450 & 0,220 & 2,048 & $\mathbf{0 , 0 4 1}$ \\
\hline Sistemas de Restrições $\rightarrow$ & SISTR $\rightarrow$ AINT & $-0,048$ & 0,337 & 0,409 & 0,683 \\
Formação de Redes & SISTR $\rightarrow$ MOBA & $-0,092$ & 0,186 & 0,259 & 0,796 \\
& SISTR $\rightarrow$ PROB & $-0,006$ & 0,216 & 0,360 & 0,719 \\
& SISTR $\rightarrow$ REC & $-0,202$ & 0,201 & 0,027 & 0,978
\end{tabular}

Nota: Avaliação do modelo estrutural. R²: Atores Humanos e Não Humanos (AHNH) = 0,107; Atração de Interesses $($ AINT) $=0,234$; Mobilização dos Aliados $($ MOBA $)=0,122$; Problematização $(\mathrm{PROB})=0,235$; Recrutamento $(\mathrm{REC})=$ 0,205. Relevância Preditiva (Q2): $\mathrm{AHNH}=0,008 ; \mathrm{AINT}=0,086 ; \mathrm{MOBA}=0,041 ; \mathrm{PROB}=0,134 ; \mathrm{REC}=0,055$. Fonte: Dados da pesquisa.

Os sistemas de controle interativo também vislumbram participação significativa no processo de atração de interesses, fruto do alinhamento da ideia que ocorre a partir de artefatos e mecanismos de atratividade (Callon, 1986). Rodger (2007) argumenta que a ANT possui como foco a transformação de redes heterogêneas em redes alinhadas, que podem ser compostas por indivíduos, grupos, organizações, tecnologias, animais, entre outros. Nesse aspecto, a flexibilidade presente nos sistemas de controle interativo mostra-se um elemento de atratividade para a formação de novas alianças no ambiente das incubadoras, uma vez que os atores pertencentes a essa rede estão sujeitos a elevados níveis de incerteza no que tange ao processo inovador. Dessa forma, precisam alcançar segurança para guiar o comportamento dos atores na rede, que se edifica pelos sistemas de controle interativo.

O processo de recrutamento de atores também recebe influência dos sistemas de controle interativo. Esta fase consiste na criação da rede-de-atores, cujo objetivo é construir um acordo entre os atores sobre os seus interesses (Alcouffe et al., 2008). Kikis (2012) assevera que a rede emergente é coordenada e alinhada ao seu objetivo fundamental. Neste processo, alguns indivíduos são considerados centrais, enquanto outros são aliados permanentes ou temporários. Assim, o elemento técnico, que representa os sistemas de controle interativo, contribui para esta fase. Para as incubadoras de empresas e para os atores humanos e não-humanos presentes na mesma, este resultado indica que os designers dos sistemas de controle interativo devem identificar a parte interessada na rede, de modo a buscar alinhamento dessas caraterísticas.

Antes de adentrar na análise da relação entre pressões ambientais e formação de redes, mediadas pelos SCG, cabe esclarecer que na literatura discutem-se dois tipos de mediação: completa e parcial (Nitzl, Roldan, \& Cepeda, 2016). A mediação é completa quando a presença da Variável Mediadora (VM) na relação Variável Independente (VI) $\rightarrow$ Variável Dependente (VD) ficará enfraquecida ou poderá chegar a ser nula. Nessas condições, Vieira (2009) aborda que se o valor for nulo, indica que a variável mediadora absorveu o efeito da VI sobre a VD, cujo processo é conhecido 
como mediação completa ou pura, tornando a relação não significativa. A mediação parcial pode ser complementar ou competitiva (Nitzl et al., 2016).

Existem diversas maneiras de analisar a mediação em um modelo estrutural (Vieria, 2009). Neste estudo, optou-se por utilizar o exame da mediação pelo procedimento do produto dos coeficientes. Esse consiste em dividir a estimativa do efeito da mediadora por seu erro-padrão e comparar esse valor com uma distribuição normal padronizada (MacKinnon, Lockwood, Hoffman, West, \& Sheets, 2002). Entre as fórmulas de comparação, baseadas no erro padronizado, tem-se aplicado três procedimentos: teste de Sobel (Sobel, 1982); teste de Aroian (Aroian, 1944); e teste de Goodman (Goodman,1960). Em consonância com o preconizado por Baron e Kenny (1986), realizaram-se os três testes.

Tabela 7

Teste de Sobel, Aroian e Goodman - Condições Econômicas

\begin{tabular}{|c|c|c|c|c|c|c|c|}
\hline \multirow{2}{*}{$\begin{array}{c}\text { Relação } \\
\text { Estrutural }\end{array}$} & \multirow{2}{*}{ Dimensão } & \multicolumn{2}{|c|}{ Teste de Sobel } & \multicolumn{2}{|c|}{ Teste de Aroian } & \multicolumn{2}{|c|}{ Teste de Goodman } \\
\hline & & Teste $\mathbf{T}$ & P Value & Teste $\mathbf{T}$ & P Value & Test $\mathbf{T}$ & P Value \\
\hline \multirow{4}{*}{1} & $\mathrm{CECON} \rightarrow \mathrm{SISTC} \rightarrow \mathrm{AHNH}$ & 0,1573 & 0,8750 & 0,1437 & 0,8858 & 0,1758 & 0,8605 \\
\hline & $\mathrm{CECON} \rightarrow \mathrm{SISTDC} \rightarrow \mathrm{AHNH}$ & $-0,2657$ & 0,7904 & $-0,2571$ & 0,7971 & 0,2752 & 0,7831 \\
\hline & $\mathrm{CECON} \rightarrow \mathrm{SISTIC} \rightarrow \mathrm{AHNH}$ & 0,9074 & 0,3642 & 0,8541 & 0,3931 & 0,9722 & 0,3310 \\
\hline & $\mathrm{CECON} \rightarrow$ SISTR $\rightarrow$ AHNH & 0,4006 & 0,6887 & 0,3576 & 0,7206 & 0,4642 & 0,6425 \\
\hline \multirow{4}{*}{2} & $\mathrm{CECON} \rightarrow \mathrm{SISTC} \rightarrow \mathrm{AINT}$ & 1,1730 & 0,2408 & 1,0963 & 0,2730 & 1,2686 & 0,2046 \\
\hline & $\mathrm{CECON} \rightarrow$ SISTDC $\rightarrow$ AINT & $-1,5822$ & 0,1136 & $-1,5393$ & 0,1237 & $-1,6289$ & 0,1033 \\
\hline & $\mathrm{CECON} \rightarrow$ SISTIC $\rightarrow$ AINT & 1,7526 & $\mathbf{0 , 0 7 9 7}$ & 1,6860 & 0,0918 & 1,8278 & 0,0676 \\
\hline & CECON $\rightarrow$ SISTR $\rightarrow$ AINT & $-0,2558$ & 0,7981 & $-0,2277$ & 0,8199 & $-0,2978$ & 0,7659 \\
\hline \multirow{4}{*}{3} & $\mathrm{CECON} \rightarrow$ SISTC $\rightarrow$ MOBA & 1,0545 & 0,2916 & 0,9810 & 0,3266 & 1,1475 & 0,2512 \\
\hline & $\mathrm{CECON} \rightarrow$ SISTDC $\rightarrow$ MOBA & 0,3352 & 0,7374 & 0,3244 & 0,7456 & 0,3472 & 0,7456 \\
\hline & $\mathrm{CECON} \rightarrow$ SISTIC $\rightarrow$ MOBA & 0,7020 & 0,4827 & 0,6587 & 0,5101 & 0,7552 & 0,4501 \\
\hline & CECON $\rightarrow$ SISTR $\rightarrow$ MOBA & $-0,3520$ & 0,7248 & $-0,3139$ & 0,7536 & $-0,4086$ & 0,6828 \\
\hline
\end{tabular}

\begin{tabular}{clrrrrrr}
\hline \multirow{2}{*}{$\begin{array}{c}\text { Relação } \\
\text { Estrutural }\end{array}$} & \multicolumn{2}{c}{ Dimensão } & \multicolumn{2}{c}{ Teste de Sobel } & \multicolumn{2}{c}{ Teste de Aroian } & \multicolumn{2}{c}{ Teste de Goodman } \\
\cline { 3 - 8 } & & \multicolumn{1}{c}{ Teste T } & $\boldsymbol{P}$ Value & \multicolumn{1}{c}{ Teste T } & $\boldsymbol{P}$ Value & Test T & $\boldsymbol{P}$ Value \\
\hline \multirow{4}{*}{4} & CECON $\rightarrow$ SISTC $\rightarrow$ PROB & 1,2611 & 0,2073 & 1,1830 & 0,2368 & 1,3570 & 0,1748 \\
& CECON $\rightarrow$ SISTDC $\rightarrow$ PROB & $-0,1098$ & 0,9126 & $-0,1062$ & 0,9154 & $-0,1137$ & 0,9095 \\
& CECON $\rightarrow$ SISTIC $\rightarrow$ PROB & 1,2990 & 0,1939 & 1,2328 & 0,2176 & 1,3771 & 0,1685 \\
& CECON $\rightarrow$ SISTR $\rightarrow$ PROB & $-0,0278$ & $-0,0324$ & $-0,0247$ & 0,9803 & $-0,0324$ & 0,9803 \\
\hline \multirow{4}{*}{5} & CECON $\rightarrow$ SISTC $\rightarrow$ REC & 1,3540 & 0,1757 & 1,2757 & 0,2021 & 1,4489 & 0,1474 \\
& CECON $\rightarrow$ SISTDC $\rightarrow$ REC & $-1,3031$ & 0,1925 & $-1,2655$ & 0,2057 & $-1,3443$ & 0,1789 \\
& CECON $\rightarrow$ SISTIC $\rightarrow$ REC & 1,6107 & 0,1072 & 1,5422 & 0,1230 & 1,6893 & $\mathbf{0 , 0 9 1 2}$ \\
& CECON $\rightarrow$ SISTR $\rightarrow$ REC & $-0,8920$ & 0,3724 & $-0,8109$ & 0,4174 & $-1,0036$ & 0,3156 \\
\hline
\end{tabular}

Legenda: 1= Condições Econômicas $\rightarrow$ Sistemas de Controle Gerencial $\rightarrow$ Atores Humanos e Não-Humanos; $2=$ Condições Econômicas $\rightarrow$ Sistemas de Controle Gerencial $\rightarrow$ Atração de Interesses; $3=$ Condições Econômicas $\rightarrow$ Sistemas de Controle Gerencial $\rightarrow$ Mobilização dos Aliados; $4=$ Condições Econômicas $\rightarrow$ Sistemas de Controle Gerencial $\rightarrow$ Problematização; $5=$ Condições Econômicas $\rightarrow$ Sistemas de Controle Gerencial $\rightarrow$ Recrutamento. Fonte: Dados da pesquisa.

Alternativamente, pode-se adotar um procedimento não paramétrico (bootstrap) para testar os coeficientes e sua significância (Hair Jr. et al., 2014). A estimação do bootstrapping foi realizada conforme ensinamentos de Hair Jr. et al. (2014). O processo de estimação do bootstrapping serviu para extrair os coeficientes de caminhos para as relações diretas e indiretas ( $n=500$, com reposição). Após a geração dos coeficientes de caminho, realizaram-se os testes de Sobel, Aroian e Goodman, a fim de verificar as relações significantes entre as variáveis do modelo estrutural, em especial a variável mediadora.

Para a realização dos testes de Sobel, Aroian e Goodman, contou-se com o apoio do software disponível no link http://quantpsy.org/sobel/sobel.htm. Hair Jr. et al. (2014) destacam que para a confirmação do Teste de Sobel, é necessário que o valor crítico para uma distribuição bicaudal e distribuição normal tenha nível de significância maior ou igual a 0,05 , ou teste $\mathrm{Z}$ acima de $\pm 1,96$. Na 
Tabela 7, apresentam-se os resultados dos testes de Sobel, Aroian e Goodman para Condições Econômicas.

Pelas estatísticas evidenciadas na Tabela 7, a variável condições econômicas apresentou nos testes de Sobel uma relação relevante. Nos testes de Aroian e Goodman apresentou uma e três relações significativas, respectivamente, todas ao nível de 0,10. As dimensões sistemas de controle gerencial, em que foram encontradas correlações significativas, referem-se aos sistemas de controle diagnóstico e aos sistemas de controle interativo. Na sequência, da mesma forma realizaram os testes de Sobel, Aroian e Goodman para a variável condições político-legais, conforme demonstrado na Tabela 8.

Tabela 8

Teste de Sobel, Aroian e Goodman - Condições Político-Legais

\begin{tabular}{|c|c|c|c|c|c|c|c|}
\hline \multirow{2}{*}{$\begin{array}{c}\text { Relação } \\
\text { Estrutural }\end{array}$} & \multirow{2}{*}{ Dimensão } & \multicolumn{2}{|c|}{ Teste Sobel } & \multicolumn{2}{|c|}{ Teste Aroian } & \multicolumn{2}{|c|}{ Test Goodman } \\
\hline & & Teste T & P Value & Teste T & P Value & Test T & P Value \\
\hline \multirow{4}{*}{1} & $\mathrm{CPL} \rightarrow \mathrm{SISTC} \rightarrow \mathrm{AHNH}$ & 0,1555 & 0,8765 & 0,1063 & 0,9153 & $\mathrm{NaN}$ & $\mathrm{NaN}$ \\
\hline & $\mathrm{CPL} \rightarrow \mathrm{SISTDC} \rightarrow \mathrm{AHNH}$ & 0,2413 & 0,8093 & 0,1284 & 0,8978 & $\mathrm{NaN}$ & $\mathrm{NaN}$ \\
\hline & $\mathrm{CPL} \rightarrow \mathrm{SISTIC} \rightarrow \mathrm{AHNH}$ & $-0,1655$ & 0,8686 & $-0,1159$ & 0,9077 & $\mathrm{NaN}$ & $\mathrm{NaN}$ \\
\hline & $\mathrm{CPL} \rightarrow \mathrm{SISTR} \rightarrow \mathrm{AHNH}$ & 0,3014 & 0,7631 & 0,1560 & 0,8761 & $\mathrm{NaN}$ & $\mathrm{NaN}$ \\
\hline \multirow{4}{*}{2} & $\mathrm{CPL} \rightarrow \mathrm{SISTC} \rightarrow \mathrm{AINT}$ & 0,7672 & 0,4430 & 0,6570 & 0,5112 & 0,9615 & 0,3363 \\
\hline & $\mathrm{CPL} \rightarrow \mathrm{SISTDC} \rightarrow \mathrm{AINT}$ & 0,5410 & 0,5885 & 0,4747 & 0,6350 & 0,6463 & 0,5181 \\
\hline & $\mathrm{CPL} \rightarrow \mathrm{SISTIC} \rightarrow$ AINT & $-0,1675$ & 0,8670 & $-0,1543$ & 0,8774 & $-0,1848$ & 0,8534 \\
\hline & $\mathrm{CPL} \rightarrow \mathrm{SISTR} \rightarrow$ AINT & $-0,2233$ & 0,8233 & $-0,1021$ & 0,9186 & $\mathrm{NaN}$ & $\mathrm{NaN}$ \\
\hline \multirow{4}{*}{3} & $\mathrm{CPL} \rightarrow \mathrm{SISTC} \rightarrow \mathrm{MOBA}$ & 0,7309 & 0,4648 & 0,6095 & 0,5422 & 0,9750 & 0,3295 \\
\hline & $\mathrm{CPL} \rightarrow \mathrm{SISTDC} \rightarrow \mathrm{MOBA}$ & $-0,2897$ & 0,7720 & $-0,1598$ & 0,8730 & $\mathrm{NaN}$ & $\mathrm{NaN}$ \\
\hline & $\mathrm{CPL} \rightarrow \mathrm{SISTIC} \rightarrow \mathrm{MOBA}$ & $-0,1637$ & 0,9219 & $-0,0980$ & 0,8700 & $\mathrm{NaN}$ & $\mathrm{NaN}$ \\
\hline & $\mathrm{CPL} \rightarrow \mathrm{SISTR} \rightarrow \mathrm{MOBA}$ & $-0,2790$ & 0,7803 & $-0,1384$ & 0,7803 & $\mathrm{NaN}$ & $\mathrm{NaN}$ \\
\hline \multirow{4}{*}{4} & $\mathrm{CPL} \rightarrow \mathrm{SISTC} \rightarrow \mathrm{PROB}$ & 0,7903 & 0,4294 & 0,6894 & 0,4906 & 0,9541 & 0,3400 \\
\hline & $\mathrm{CPL} \rightarrow \mathrm{SISTDC} \rightarrow \mathrm{PROB}$ & 0,1078 & 0,9141 & 0,0541 & 0,9569 & $\mathrm{NaN}$ & $\mathrm{NaN}$ \\
\hline & $\mathrm{CPL} \rightarrow \mathrm{SISTIC} \rightarrow \mathrm{PROB}$ & $-0,1669$ & 0,8675 & $-0,1390$ & 0,8894 & $-0,2231$ & 0,8234 \\
\hline & $\mathrm{CPL} \rightarrow \mathrm{SISTR} \rightarrow \mathrm{PROB}$ & $-0,0277$ & 0,9779 & $-0,0113$ & 0,9910 & $\mathrm{NaN}$ & $\mathrm{NaN}$ \\
\hline \multirow{4}{*}{5} & $\mathrm{CPL} \rightarrow \mathrm{SISTC} \rightarrow \mathrm{REC}$ & 0,8117 & 0,4170 & 0,7212 & 0,4708 & 0,9479 & 0,3432 \\
\hline & $\mathrm{CPL} \rightarrow \mathrm{SISTDC} \rightarrow \mathrm{REC}$ & 0,5266 & 0,5984 & 0,4380 & 0,6614 & 0,7072 & 0,4794 \\
\hline & $\mathrm{CPL} \rightarrow \mathrm{SISTIC} \rightarrow \mathrm{REC}$ & $-0,1674$ & 0,8671 & $-0,1505$ & 0,8804 & $-0,1917$ & 0,8480 \\
\hline & $\mathrm{CPL} \rightarrow \mathrm{SISTR} \rightarrow \mathrm{REC}$ & $-0,4070$ & 0,6840 & $-0,3010$ & 0,7634 & $-0,9806$ & 0,3268 \\
\hline
\end{tabular}

Legenda: 1=Condições Político-Legais $\rightarrow$ Sistemas de Controle Gerencial $\rightarrow$ Atores Humanos e Não-Humanos; $2=$ Condições Político-Legais $\rightarrow$ Sistemas de Controle Gerencial $\rightarrow$ Atração de Interesses; 3=Condições PolíticoLegais $\rightarrow$ Sistemas de Controle Gerencial $\rightarrow$ Mobilização dos Aliados; 4=Condições Político-Legais $\rightarrow$ Sistemas de Controle Gerencial $\rightarrow$ Problematização; $5=$ Condições Político-Legais $\rightarrow$ Sistemas de Controle Gerencial $\rightarrow$ Recrutamento. Fonte: Dados da pesquisa.

Na Tabela 8, nota-se que a variável condições político-legais nos testes de Sobel, Aroian e Goodman não apresentou relações significativas e relevantes, com sig $\leq 0,05$ ou teste $\mathrm{z} \pm 1,96$. $\mathrm{Na}$ continuidade dos testes para verificação da mediação, na Tabela 9 apresentam-se os testes de Sobel, Aroian e Goodman para a variável condições tecnológicas.

Na Tabela 9 verifica-se que os três testes elencados não foram significativos para os caminhos testados no modelo estrutural, a partir da variável condições tecnológicas, fato esse que contribui para a apresentação de uma possível não mediação dos SCG a partir desta variável. Das 60 relações verificadas pelos testes de Sobel, Aroian e Goodman, apenas três dimensões mostraram-se significativas estatisticamente.

Na Tabela 10, demonstram-se os resultados que foram confirmados pela mediação dos sistemas de controle gerencial. Para que a mediação fosse confirmada como completa, o produto dos caminhos entre a VI $\rightarrow \mathrm{VM} \rightarrow \mathrm{VD}$ deveria ser significativo e o valor do produto $\mathrm{VI} \rightarrow \mathrm{VD}$ não significativo. Caso o caminho VI $\rightarrow$ VD fosse significativo, justificar-se-ia a mediação, sendo esta parcial, complementar ou competitiva (Nitzl et al., 2016). 
Tabela 9

Teste de Sobel, Aroian e Goodman - Condições Tecnológicas

\begin{tabular}{|c|c|c|c|c|c|c|c|}
\hline \multirow{2}{*}{$\begin{array}{c}\text { Relação } \\
\text { Estrutural }\end{array}$} & \multirow{2}{*}{ Dimensão } & \multicolumn{2}{|c|}{ Teste Sobel } & \multicolumn{2}{|c|}{ Teste Aroian } & \multicolumn{2}{|c|}{ Test Goodman } \\
\hline & & Teste T & P Value & Teste $\mathbf{T}$ & P Value & Test T & $P$ Value \\
\hline \multirow{4}{*}{1} & $\mathrm{CETC} \rightarrow \mathrm{SISTC} \rightarrow \mathrm{AHNH}$ & $-0,1478$ & 0,8825 & $-0,0609$ & 0,9514 & $\mathrm{NaN}$ & $\mathrm{NaN}$ \\
\hline & $\mathrm{CETC} \rightarrow \mathrm{SISTDC} \rightarrow \mathrm{AHNH}$ & 0,2438 & 0,8074 & 0,1345 & 0,8930 & $\mathrm{NaN}$ & $\mathrm{NaN}$ \\
\hline & $\mathrm{CETC} \rightarrow \mathrm{SISTIC} \rightarrow \mathrm{AHNH}$ & 0,2044 & 0,8380 & 0,1438 & 0,8856 & $\mathrm{NaN}$ & $\mathrm{NaN}$ \\
\hline & $\mathrm{CETC} \rightarrow \mathrm{SISTR} \rightarrow \mathrm{AHNH}$ & $-0,0531$ & 0,9576 & $-0,0203$ & 0,9838 & $\mathrm{NaN}$ & $\mathrm{NaN}$ \\
\hline \multirow{4}{*}{2} & CETC $\rightarrow$ SISTC $\rightarrow$ AINT & $-0,4051$ & 0,6854 & $-0,3329$ & 0,7392 & $-0,5624$ & 0,5738 \\
\hline & $\mathrm{CETC} \rightarrow$ SISTDC $\rightarrow$ AINT & 0,5716 & 0,5676 & 0,5022 & 0,6155 & 0,6809 & 0,4959 \\
\hline & $\mathrm{CETC} \rightarrow$ SISTIC $\rightarrow$ AINT & 0,2083 & 0,8350 & 0,1920 & 0,8478 & 0,2298 & 0,8183 \\
\hline & $\mathrm{CETC} \rightarrow \mathrm{SISTR} \rightarrow$ AINT & 0,0525 & 0,9582 & 0,0134 & 0,9893 & $\mathrm{NaN}$ & $\mathrm{NaN}$ \\
\hline \multirow{4}{*}{3} & CETC $\rightarrow$ SISTC $\rightarrow$ MOBA & $-0,3995$ & 0,6895 & $-0,3138$ & 0,7537 & $-0,6491$ & 0,5163 \\
\hline & $\mathrm{CETC} \rightarrow \mathrm{SISTDC} \rightarrow \mathrm{MOBA}$ & $-0,2941$ & 0,7687 & $-0,1675$ & 0,8670 & $\mathrm{NaN}$ & $\mathrm{NaN}$ \\
\hline & $\mathrm{CETC} \rightarrow$ SISTIC $\rightarrow$ MOBA & 0,2010 & 0,8407 & 0,1215 & 0,9033 & $\mathrm{NaN}$ & $\mathrm{NaN}$ \\
\hline & $\mathrm{CETC} \rightarrow$ SISTR $\rightarrow$ MOBA & 0,0530 & 0,9577 & 0,0180 & 0,9856 & $\mathrm{NaN}$ & $\mathrm{NaN}$ \\
\hline \multirow{4}{*}{4} & CETC $\rightarrow$ SISTC $\rightarrow$ PROB & $-0,4084$ & 0,6830 & $-0,3454$ & 0,7298 & $-0,5264$ & 0,5986 \\
\hline & $\mathrm{CETC} \rightarrow \mathrm{SISTDC} \rightarrow \mathrm{PROB}$ & 0,1081 & 0,9139 & 0,0566 & 0,9548 & $\mathrm{NaN}$ & $\mathrm{NaN}$ \\
\hline & $\mathrm{CETC} \rightarrow$ SISTIC $\rightarrow$ PROB & 0,2071 & 0,8359 & 0,1728 & 0,8628 & 0,2762 & 0,7824 \\
\hline & $\mathrm{CETC} \rightarrow$ SISTR $\rightarrow$ PROB & 0,0247 & 0,9803 & 0,0015 & 0,9988 & $\mathrm{NaN}$ & $\mathrm{NaN}$ \\
\hline \multirow{4}{*}{5} & CETC $\rightarrow$ SISTC $\rightarrow$ REC & $-0,4113$ & 0,6809 & $-0,3573$ & 0,7209 & $-0,5007$ & 0,6166 \\
\hline & $\mathrm{CETC} \rightarrow \mathrm{SISTDC} \rightarrow \mathrm{REC}$ & 0,5547 & 0,5791 & 0,4627 & 0,6436 & 0,7394 & 0,4597 \\
\hline & CETC $\rightarrow$ SISTIC $\rightarrow$ REC & 0,2081 & 0,8352 & 0,1871 & 0,8516 & 0,2381 & 0,8118 \\
\hline & CETC $\rightarrow$ SISTR $\rightarrow$ REC & 0,0535 & 0,9573 & 0,0379 & 0,9697 & 0,4750 & 0,6348 \\
\hline
\end{tabular}

Legenda: 1=Condições Tecnológicas $\rightarrow$ Sistemas de Controle Gerencial $\rightarrow$ Atores Humanos e Não-Humanos; 2= Condições Tecnológicas $\rightarrow$ Sistemas de Controle Gerencial $\rightarrow$ Atração de Interesses; 3=Condições Tecnológicas $\rightarrow$ Sistemas de Controle Gerencial $\rightarrow$ Mobilização dos Aliados; 4=Condições Tecnológicas $\rightarrow$ Sistemas de Controle Gerencial $\rightarrow$ Problematização; 5=Condições Tecnológicas $\rightarrow$ Sistemas de Controle Gerencial $\rightarrow$ Recrutamento. Fonte: Dados da pesquisa.

Tabela 10

Confirmação da mediação dos SCG na relação entre pressões ambientais e formação de redes

\begin{tabular}{|c|c|c|c|c|c|c|}
\hline \multirow{2}{*}{$\begin{array}{c}\text { Relações entre as variáveis com } \\
\text { mediação dos SCG }\end{array}$} & \multicolumn{2}{|c|}{ Teste Sobel } & \multicolumn{2}{|c|}{ Teste Aroian } & \multicolumn{2}{|c|}{ Test Goodman } \\
\hline & Teste T & P Value & Teste $\mathbf{T}$ & $P$ Value & Test $\mathbf{T}$ & $P$ Value \\
\hline 1. CECON $\rightarrow$ SISTIC $\rightarrow$ AINT & 1,7526 & $\mathbf{0 , 0 7 9 7}$ & 1,686 & 0,0918 & 1,8278 & 0,0676 \\
\hline \multirow{2}{*}{$\begin{array}{l}\text { Relações entre as variáveis sem } \\
\text { mediação dos SCG }\end{array}$} & \multicolumn{2}{|c|}{ Bootstrapping } & \multirow{2}{*}{\multicolumn{4}{|c|}{ Mediação completa }} \\
\hline & Teste $\mathbf{T}$ & P Value & & & & \\
\hline 2. $\mathrm{CECON} \rightarrow \mathrm{AINT}$ & 0,116 & $\mathbf{0 , 3 3 8}$ & & & & \\
\hline
\end{tabular}

Legenda: 1=Condições Econômicas $\rightarrow$ Sistemas de Controle Interativo $\rightarrow$ Atração de Interesses; 2=Condições Econômicas $\rightarrow$ Atração de Interesses.

Fonte: Dados da pesquisa.

Na Tabela 10, os coeficientes e os p-values dos testes de Sobel, Aroian e Goodman indicam que o sistema interativo de controle se apresenta significativo e com efeito positivo na mediação entre condições econômicas e processo de atração de interesses na rede-de-atores. Assim, aceita-se parcialmente a $\mathrm{H}_{3}$. Nessas condições, a variável mediadora pode induzir mudanças e alterar as associações de atores na rede, as quais podem ser aleatórias e imprevisíveis (Hyvönen et al., 2008). Pelo resultado e decisão quanto à hipótese $\mathrm{H}_{3}$, infere-se que o processo de atração de interesses é redesenhado a partir das condições econômicas, mediado pelos sistemas de controle interativo. O uso do controle interativo visa preparar a organização para que a permeabilidade das inseguranças e incertezas estratégicas, no contexto organizacional, ocorra de modo satisfatório na condução dos negócios (Simons, 1995).

Desse modo, os sistemas de controle interativo podem fornecer orientação e motivar os atores, o que afeta positivamente o processo de atração de interesses, enquanto os interesses dos atores humanos e não-humanos são capazes de modificar e reconfigurar as redes formadas em determinado contexto (Latour, 1999). Portanto, os SGC, na sua dimensão interativa, apresentam-se como um meio 
de atrair interesses para formar alianças robustas entre os atores. A atração de interesses pode ser comercial, política, editorial, intelectual ou evolução de carreira (Alcouffe et al., 2008). Essa configuração sociotécnica envolve a integração dos atores humanos e os componentes tecnológicos, que representam a atratividade dos negócios desenvolvidos na incubadora de empresa.

\subsection{Discussão dos resultados}

Os resultados indicam que as pressões ambientais, entendidas por condições econômicas, influenciam os SCG. Portanto, o ambiente econômico influencia positivamente a atuação dos mecanismos inscritos nas crenças e restrições e no controle diagnóstico e interativo no ambiente das incubadoras de empresas. As condições econômicas interferem na forma de configuração e uso dos SCG (Rautiainen \& Scapens, 2013), principalmente em ambientes inovadores. Esse resultado revela a permeabilidade das condições econômicas nos SCG, o que implica também a alteração do objetivo dos SCG, à medida que as condições econômicas alteram o desempenho e o comportamento dos participantes desse ambiente.

A incubadora de empresas possui o papel de atuar como um ator interveniente da relação entre startups e mercado. Portanto, a incorporação de condições econômicas nos mecanismos de controle gerencial representa um alerta para os gestores desses empreendimentos, à medida que os SCG respondem ao contexto econômico. Assim, acompanhar metas, monitorar resultados, criar um ambiente para fazer frente às incertezas organizacionais é um processo que perpassa as condições econômicas de uma nação. Além disso, reconhecer esses resultados pode contribuir com as incubadoras, no que tange à auxiliar as startups a superar os desafios que se apresentam para assegurar a continuidade organizacional e a falta de recursos inerente (Kljuno \& Gureeva, 2017).

Quanto a reconhecer os SCG como antecedentes do processo de formação de rede-de-atores humanos e não-humanos, destaca-se que o processo de recrutamento recebe influência positiva e significativa dos sistemas de crenças e dos sistemas de controle interativo. O processo de atração de interesses recebe influência dos sistemas de controle diagnóstico e interativo. Assim, quanto ao primeiro processo, de formação da rede-de-atores, argumenta-se que os valores e crenças e os processos de uso interativo dos SCG das incubadoras alinham-se ao processo de encontrar para os parceiros relacionamentos interorganizacionais. Quanto ao segundo processo, de formação da redede-atores, os interesses dos participantes da rede recebem influência de como os recursos e as pessoas serão geridas nesse processo, em termos de controle diagnóstico. Esses resultados reforçam que os processos inovadores são custosos para as organizações. Por isso, buscam parceiros para equacionar esses gastos, o que demanda equilíbrio entre controle e flexibilização, para que o processo inovador aconteça.

O recrutamento alinha-se a uma passagem obrigatória para a construção da rede e dos papéis a serem assumidos pelos atores. Assim, sugere-se que os gestores das incubadoras reconheçam os valores e crenças e aspectos de controle interativo dos SCG usados pelos atores, sejam eles banco de fomento e financiamento, fundações de amparo à pesquisa, universidades, ou serviços de apoio à inovação e tecnologia para micro e pequenas empresas. Esse reconhecimento é importante para que o inter-relacionamento a ser estabelecido por estes se concretize e possa resultar no alcance do objetivo da incubadora. Quanto à atração de interesses, pauta-se que as incubadoras de empresas estão preocupadas com o controle dos recursos financeiros. Por mais que esteja em um ambiente inovador, o espaço da incubadora também demanda segurança. Assim, o uso dos SCG diagnóstico possui papel importante no processo de formação de redes.

Os resultados denotam que a ANT, a partir das suas construções coletivas e sociotécnicas (Latour, 1999), favorece a compreensão da interação das condições econômicas e dos sistemas de controle interativo com a atração de interesses, dimensão do processo de formação da rede-de-atores nas incubadoras de empresas. As construções sociotécnicas ocorrem centrando-se no alinhamento dos interesses dos atores envolvidos nas atividades de avaliação, direção e monitoramento da interação do ambiente econômico com os sistemas de controle interativo. Assim, a incorporação das 
características dos sistemas de controle interativo na relação entre condições econômicas e formação de rede-de-atores, na sua dimensão atração de interesses, mostrou-se significativa e positivamente relacionada.

O uso dos sistemas de controle interativo permite que o processo de atração de interesses, no campo das incubadoras de empresas, ocorra de forma dinâmica e consubstanciado em controles que absorvem as incertezas e proporcionam um desafio contínuo no ambiente inovador, se considerado que os processos nesses ambientes dependem de aprovações, desde mercadológicas até financiamentos. Esse processo contribui para a formação de alianças, causando efeitos nos atores envolvidos (Latour, 1987). Assim, as incubadoras precisam ser atrativas para atender às necessidades dos atores envolvidos nos processos inovadores. As redes nas incubadoras de empresas se formam pelo alinhamento de interesses, mediado pelos SCG, na sua dimensão interativa, e das condições econômicas atreladas ao ambiente inovador.

Os sistemas de controle interativo atuam como mediadores entre o processo de formação de redes, na dimensão atração de interesses, e as condições econômicas. Os sistemas de controle interativo consideram as constantes mudanças de natureza estratégica global da organização. Exige a atenção de todos os níveis de gestão. Presume que os dados são melhor analisados em um ambiente face-a-face, em grupos que incluem todos os níveis de funcionários, e estimula essas discussões regulares (Simons, 1995). Neste sentido, os SCG desempenham papel relevante na criação das condições adequadas para trazer os aliados junto à rede a ser constituída, bem como construir acordos entre as partes sobre os seus interesses. Considerando que a rede de atores é frágil e temporária, os sistemas de controle interativo buscam estimular o aprendizado por meio de estratégicas competitivas. Esses sistemas estão alinhados às mudanças do ambiente e necessidades de inovação, comuns nas incubadoras.

Os sistemas de controle interativo apresentam-se como receptores das condições econômicas e podem contribuir na atração de aliados para a rede de atores nas incubadoras. Dessa forma, é salutar que seus gestores busquem desenvolver medidas que permitam mapear com frequência as condições econômicas locais, regionais, nacionais e até mesmo internacionais, visto que os processos globalizatórios têm interferido no desenvolvimento dos negócios inovadores do país. Por mais custoso que seja o processo de estruturação de um SCG, esse mostrou-se pertinente no ambiente das incubadoras e respondeu às expectativas e demandas desse ambiente inovador. Os SCG interativo ainda demonstraram contribuir para o alcance de parceiros com propostas alinhadas aos interesses das incubadoras.

Dessa forma, para os atores do ambiente das incubadoras de empresas, criar alianças robustas, por meio de uma série de artefatos e mecanismos de atratividade (Callon, 1986), apresenta-se uma tarefa desafiadora. Contribuindo para esta colocação, incentiva-se que os elementos presentes na flexibilidade dos sistemas de controle interativo sejam considerados quando os atores se depararem com questões de cunho econômico, relacionadas ao aumento no nível de pressões, integração global do comércio e diminuição da demanda no mercado (interno e externo). Os resultados desta pesquisa demonstram que os SCG têm a capacidade de neutralizar essas questões e contribuir positivamente para a formação da rede-de-atores.

Justesen e Mouritsen (2011) sinalizam que a ANT, como lente de pesquisa na Contabilidade Gerencial, ainda demanda atenção dos pesquisadores, dado sua ênfase limitada. Nesse sentido, esta pesquisa apoiou-se em estudos diversos da área organizacional, no intuito de demonstrar a influência que os SCG podem exercer sobre as pressões ambientais e a formação de redes. Averiguou-se, neste estudo em incubadoras de empresas, a relação dos SCG com colisões econômicas, político-legais e tecnológicas em organizações, conforme ensinamentos de Whittle e Mueller (2010). As evidências do papel mediador dos SCG na relação entre pressões ambientais e formação de redes fornecem insights para novas pesquisas. 


\section{CONCLUSÕES}

As evidências empíricas da influência das pressões ambientais na formação de rede-de-atores em incubadoras de empresas, mediadas pelos SCG, fornecem provocações relativas a forma como as redes-de-atores são formadas e como os SCG podem fomentá-las, ao fornecer subsídios para o seu desenvolvimento. Inicialmente constatou-se que as condições ambientais influenciam nos SCG de forma positiva. Ademais, os aspectos relacionados ao recrutamento na rede-de-atores são influenciados pelos sistemas de controle interativo das incubadoras. Por fim, a atração e o alinhamento de interesses recebe influência positiva dos sistemas de controle diagnóstico e interativo. Dessa maneira, as condições econômicas passaram das áreas funcionais periféricas das incubadoras para o âmbito corporativo, no que concerne à formação de redes-de-atores humanos e não-humanos.

Os resultados desta pesquisa apresentam evidências de que os SCG medeiam a relação entre as condições econômicas e o processo de atração de interesses. Atrair atores, sejam humanos ou nãohumanos, é a chave para o alinhamento de objetivos no ambiente das incubadoras de empresas. Assim, revela-se uma relação sociotécnica no ambiente das incubadoras de empresas, na qual a interação dos sistemas de controle interativo com o ambiente de pressões econômicas conduz à atração de interesses para o desenvolvimento de alianças e fortalecimento de uma possível rede-deatores.

Os resultados da pesquisa reposicionam e fornecem reabilitação para a Contabilidade à luz de uma explicação sociológica (Justesen \& Mouritsen, 2011). Contribui-se ao inseri-la no contexto social, uma vez que tem sido tratada em pesquisas não como atuante no sistema social, mas como receptora das mudanças ambientais. Sob a ótica da ANT, as pesquisas comumente têm demonstrado que os fenômenos contábeis se apresentam momentaneamente como black-box e tornam-se coisas diferentes quando são traduzidas na prática (Justesen \& Mouritsen, 2011). As construções investigadas revelam que os sistemas de controle interativo medeiam a relação entre as condições econômicas e o processo de atração de interesses. Se este conjunto for adequadamente concebido e equacionado sob o enfoque do processo de inovação, certamente haverá ganhos nos relacionamentos nas incubadoras.

Conclui-se que as condições econômicas são incorporadas no processo de atração de interesses pelas incubadoras, sendo que os SCG intensificam este processo de modo positivo. O papel mediador dos SCG é explicado pela ANT como uma relação sociotécnica, em que elementos humanos e não-humanos, representados pelos sujeitos e pela tecnologia, estão congregados para o alcance de determinado objetivo, conferindo uma melhor compreensão da conexão entre a contabilidade e o seu contexto social. Parte das pesquisas que abordam a questão do desenvolvimento dos SCG realizamna em um nível estático e, em alguns casos, restringem-se a usar apenas parte do modelo do SCG proposto por Simons (1995). Esta investigação reforça, via evidências, a necessidade de se estudar os SCG como um pacote, como evidenciado por Speklé et al. (2017).

Contribuições teóricas são advindas da aplicação dos conceitos preconizados pela ANT no campo da Contabilidade Gerencial, em especial na análise dos efeitos dos SCG, à luz do modelo das alavancas de controle de Simons (1995), na relação entre as pressões ambientais e a formação de rede-de-atores em incubadoras de empresas. Contribui-se ao explicar os fenômenos da formação de rede-de-atores em incubadoras de empresas, a partir de discussões que permeiam os SCG e os conceitos inscritos nas contingências, entendidas como pressões ambientais. Em termos práticos, a pesquisa contribui ao apresentar que o contexto inovador das incubadoras de empresas mostra-se dependente de elementos presentes nas pressões econômicas e nos SCG, na sua dimensão de uso interativo. Isso indica que gestores devem se atentar às pressões ambientais e características dos SCG, de modo a corporificar o processo de inovação e favorecer a atração de aliados para a formação de rede-de-atores.

O alerta desta investigação às incubadoras pauta-se em três considerações. Primeira, para uma efetiva formação de rede e para o desenvolvimento de novas parcerias, recomenda-se fortemente que 
as incubadoras de empresas analisem a forma como estão monitorando as condições econômicas, pois estas parecem elementos de maior preocupação para os gestores. Até mesmo pelo perfil das incubadoras investigadas, denota-se que políticas e decisões governamentais que afetam o escopo econômico da nação, tendem a afetar o funcionamento desses empreendimentos inovadores. Segunda, aponta para a necessidade de aperfeiçoamento constante dos SCG utilizados, no sentido de buscar respostas diante das condições econômicas. Por exemplo, a dependência de recursos nesse ambiente é elevada. Assim, a divulgação pela incubadora de um edital de fomento já representa um cenário que deve ser incorporado em termos informacionais no SCG e reportado com frequência, porque as fundações de amparo também demandam informações que podem ser cruciais para a atração de interesse e, consequentemente, para a formação da rede de atores. Terceira, os gestores precisam imprimir forças constantes que permitam o controle das operações das incubadas e da formação de redes. Mas, ao mesmo tempo, precisam dar liberdade para o processo de criação e desenvolvimento de produtos e serviços inovadores. O gerenciamento dessa tensão dinâmica é tarefa chave para não atrapalhar a coordenação dos papéis dos atores dentro da rede.

As limitações deste estudo apontam lacunas para novas investigações. Recomenda-se ampliar a investigação quanto ao efeito dos SCG nas relações entre as pressões ambientais e a formação de redes-de-atores, para analisar a capacidade dos SCG de atenuar ou ampliar as forças dessas relações. Essa inquietação pode estender as discussões se forem ampliadas as tipificações de pressões ambientais e os elementos presentes na ANT. Uma aproximação com os atores humanos e nãohumanos que compõem a rede-de-atores das incubadoras pode desvendar como está disposto o processo de atração de interesse e recrutamento. Essa aproximação pode fornecer respostas sobre o porquê de outros construtos da ANT não serem percebidos pelos gestores em termos de influência dos SCG. Como as incubadoras configuram um sistema aberto, outras dimensões dos SCG podem revelar-se relacionadas ao processo de formação de redes, além de outras pressões ambientais ou as com menor evidência nesta pesquisa, podem apresentar-se relevantes.

\section{REFERÊNCIAS}

Abbad, G. D. S., \& Torres, C. V. (2002). Regressão múltipla stepwise e hierárquica em Psicologia Organizacional: Aplicações, problemas e soluções. Estudos de Psicologia (Natal), 7 (n. spec.), 19-29.

Abernethy, M. A., \& Chua, W. F. (1996). A field study of control system "redesign": The impact of institutional processes on strategic choice. Contemporary Accounting Research, 13(2), 569-606.

Alcadipani, R., \& Hassard, J. (2010). Actor-Network Theory, organizations and critique: Towards a politics of organizing. Organization, 17(4), 419-435.

Alcouffe, S., Berland, N., \& Levant, Y. (2008). Actor-networks and the diffusion of management accounting innovations: A comparative study. Management Accounting Research, 19(1), 1-17.

Aliyu, N. S., Jamil, C. Z. M., \& Mohamed, R. (2014). The mediating role of management control system in the relationship between corporate governance and the performance of bailed-out banks in Nigeria. Procedia-Social and Behavioral Sciences, 164, 613-620.

Angonese, R., \& Lavarda, C. E. F. (2017). Fatores para a implementação da mudança em sistemas de contabilidade gerencial. Enfoque: Reflexão Contábil, 36(1), 139-154.

Akrich, M., \& Latour, B. (1992) A summary of a convenient vocabulary for the semiotics of human and nonhuman assemblies. In: Bijker, W., \& Law, J. (Eds.). Shapping technology, building society: studies in sociotechnical change (p. 259-264). Cambridge, MA: TheMIT Press.

Aroian, L. A. (1944). The probability function of the product of two normally distributed variables. Annals of Mathematical Statistics, 18(1) 265-271.

Associação Nacional de Entidades Promotoras de Empreendimentos Inovadores (Anprotec). (2016). Estudo de impacto econômico: Segmento de incubadoras de empresas do Brasil. Brasília: Anprotec, Sebrae.

Badri, M. A., Davis, D., \& Davis, D. (2000). Operations strategy, environmental uncertainty and performance: A path analytic model of industries in developing countries. Omega, 28(2), 155-173.

Baron, R. M., \& Kenny, D. A. (1986). The moderator-mediator variable distinction in social psychological research: Conceptual, strategic, and statistical considerations. Journal of Personality and Social 
Psychology, 51(6), 1173.

Becker, S. D., Jagalla, T., \& Skærbæk, P. (2014). The translation of accrual accounting and budgeting and the reconfiguration of public sector accountants' identities. Critical Perspectives on Accounting, 25(45), 324-338.

Beuren, I. M., \& Vaz, P. V. C. (2016). Papel mediador do pacote do sistema de controle gerencial na relação entre estratégia ambiental e performance gerencial. Anais do Congresso de Controladoria e Contabilidade, São Paulo, 2015, SP, Brasil.

Bisbe, J., \& Otley, D. (2004). The effects of the interactive use of management control systems on product innovation. Accounting, Organizations and Society, 29(8), 709-737.

Burgess, J., Clark, J., \& Harrison, C. M. (2000). Knowledges in action: An actor network analysis of a wetland agri-environment scheme. Ecological Economics, 35(1), 119-132.

Burns, J., \& Scapens, R. W. (2000). Conceptualizing management accounting change: An institutional framework. Management Accounting Research, 11(1), 3-25.

Callon, M. (1986). Some elements of a sociology of translation: Domestication of the Scallops and the Fishermen. In: J. Law (org.). Power, action and belief: A new sociology of knowledge? (p. 196-223). London: Routledge \& Kegan.

Callon, M., \& Latour, B. (1981). Unscrewing the big leviathan: How actors macrostructure reality and how sociologists help them to do so. In: K. K. Cetina, \& A. Cicourel (orgs.). Advances in social theory and methodology: Toward an integration of micro and macro sociologies (pp. 277-303). London: Routledge \& Kegan.

Cavalcanti, M. F. R., \& Alcadipani, R. (2013). Organizações como processos e Teoria Ator-Rede: A contribuição de John Law para os estudos organizacionais. Cadernos EBAPE. BR, 11(4), 556-568.

Chenhall, R. H. (2003). Management control systems design within its organizational context: findings from contingency-based research and directions for the future. Accounting, Organizations and Society, 28(2-3), 127-168.

Chua, W. F. (1995). Experts, networks and inscriptions in the fabrication of accounting images: a story of the representation of three public hospitals. Accounting, Organizations and Society, 20(2-3), 111-145.

Cohen, J. (1988). Statistical power analysis for the behavioral sciences (2nd ed.). New York: Psychology Press.

Cruz, A. P. C., Frezatti, F., \& Bido, D. S. (2015). Estilo de liderança, controle gerencial e inovação: Papel das alavancas de controle. RAC. Revista de Administração Contemporânea, 19(6), 772-794.

Davila, A., Foster, G., \& Li, M. (2009). Reasons for management control systems adoption: Insights from product development systems choice by early-stage entrepreneurial companies. Accounting, Organizations and Society, 34(3), 322-347.

Dechow, N., \& Mouritsen, J. (2005). Enterprise resource planning systems, management control and the quest for integration. Accounting, Organizations and Society, 30(7), 691-733.

Degenhart, L., \& Beuren, I. M. (2019). Consolidação do modelo das alavancas de controle de Simons: análise sob a lente da Teoria Ator-Rede. Advances in Scientific \& Applied Accounting, 12(1), 4-23.

Elbaz, A. M. (2013). Actor-network theory, tourism organizations and the development of sustainable community livelihoods. Doctoral dissertation, School of Tourism and Hospitality Faculty of Plymouth Business School, UK.

Emsley, D. (2008). Different interpretations of a "fixed" concept: Examining Juran's cost of quality from an actor-network perspective. Accounting, Auditing \& Accountability Journal, 21(3), 375-397.

Ferreira, A., \& Otley, D. (2009). The design and use of performance management systems: An extended framework for analysis. Management Accounting Research, 20(4), 263-282.

Fornell, C., \& Larcker, D. F. (1981). Structural equation models with unobservable variables and measurement error: Algebra and statistics. Journal of Marketing Research, 18(3), 382-388.

Goodman, L. A. (1960). On the exact variance of products. Journal of the American Statistical Association, 55(292), 708-713.

Hair Jr, J. F., Hult, G. T. M., Ringle, C. M., \& Sarstedt, M. (2014). A primer on partial least squares structural equation modeling (PLS-SEM). Thousand Oaks: SAGE.

Hall, R. H. (2004). Organizações: estruturas, processos e resultados. São Paulo: Pearson.

Hannan, M. T., \& Freeman, J. (1977). The population ecology of organizations. American Journal of Sociology, 82(5), 929-964.

Henri, J. F. (2006). Management control systems and strategy: A resource-based perspective. Accounting, 
Organizations and Society, 31(6), 529-558.

Hopwood, A. G. (1987). The archeology of accounting systems. Accounting, Organizations and Society, 12(3), 207-234.

Hyvönen, T., Järvinen, J., \& Pellinen, J. (2008). A virtual integration-The management control system in a multinational enterprise. Management Accounting Research, 19(1), 45-61.

Justesen, L., \& Mouritsen, J. (2011). Effects of actor-network theory in accounting research. Accounting, Auditing \& Accountability Journal, 24(2), 161-193.

Kikis, K. (2012). Expanding the accounting profession: The case of environmental and sustainability assurance. Master's Thesis, Universiteit van Amsterdam, Amsterdam.

Kleine, C., \& Weißenberger, B. E. (2014). Leadership impact on organizational commitment: the mediating role of management control systems choice. Journal of Management Control, 24(3), 241-266.

Kljuno, A., \& Gureeva, I. (2017). Management control systems in innovative startups-A multi case study of Swedish $R \& D$ startup companies. Lund University Libraries. Recuperado em 18 janeiro, 2021, de http://lup.lub.lu.se/student-papers/record/8919061

Kober, R., Ng, J., \& Paul, B. J. (2007). The interrelationship between management control mechanisms and strategy. Management Accounting Research, 18(4), 425-452.

Lacruz, A. J., Américo, B. L., \& Carniel, F. (2017). Teoria ator-rede em estudos organizacionais: Análise da produção científica no Brasil. Cadernos EBAPE.BR, 15(3), 574-598.

Langfield-Smith, K. (1997). Management control systems and strategy: A critical review. Accounting, Organizations and Society, 22(2), 207-232.

Latour, B. (1987). Science in action: How to follow scientists and engineers through society. Cambridge: Harvard University Press.

Latour, B. (1988). The pasteurization of France. Cambridge: Harvard University Press.

Latour, B. (1999). On recalling ANT. The Sociological Review, 47(1), 15-25.

Latour, B. (2001). Pandora's hope: Essays on the reality of science studies. Cambridge: Harvard University Press.

Latour, B. (2005). Reassembling the social: An introduction to actor-network-theory. Oxford: Oxford University Press.

Law, J. (1992). Notes on the theory of the actor-network: Ordering, strategy, and heterogeneity. Systems Practice, 5(4), 379-393

Law, J. (1999). After ANT: Complexity, naming and topology. The Sociological Review, 47(S1), 1-14.

Lee, N., \& Hassard, J. (1999). Organization unbound: Actor-network theory, research strategy and institutional flexibility. Organization, 6(3), 391-404.

Lewis, M. W. (2000). Exploring paradox: Toward a more comprehensive guide. Academy of Management Review, 25(4), 760-776.

Lopes, I. F., \& Beuren, I. M. (2017). Análise das publicações internacionais de contabilidade gerencial sob a lente da Teoria Ator-Rede. Advances in Scientific and Applied Accounting, 10(2), 189-210.

Lopes, I. F., \& Beuren, I. M. (2018). Reflexos da cultura local nos sistemas de controle de incubadoras de empresas. Revista de Contabilidade e Organizações, 12, e142273.

Lowe, A. (2001). After ANT: An illustrative discussion of the implications for qualitative accounting case research. Accounting, Auditing \& Accountability Journal, 14(3), 327-351.

Lukka, K., \& Vinnari, E. (2014). Domain theory and method theory in management accounting research. Accounting, Auditing \& Accountability Journal, 27(8), 1308-1338.

MacKinnon, D. P., Lockwood, C. M., Hoffman, J. M., West, S. G., \& Sheets, V. (2002). A comparison of methods to test mediation and other intervening variable effects. Psychological Methods, 7(1), 83-104.

Malmi, T., \& Brown, D. A. (2008). Management control systems as a package-Opportunities, challenges and research directions. Management Accounting Research, 19(4), 287-300.

Martins, L. M. F. (2011). Uma perspectiva sociotécnica para a governança de tecnologia da informação baseada na Teoria Ator-Rede. Tese de Doutorado, Universidade de Coimbra, Portugal.

McLean, C., \& Hassard, J. (2004). Symmetrical absence/symmetrical absurdity: Critical notes on the production of actor-network accounts. Journal of Management Studies, 41(3), 493-519.

Melo, M. F. A. (2007). Seguindo as pipas com a metodologia da TAR. Revista do Departamento de Psicologia da UFF, 19(1), 169-185.

Mendonça, V. C., Bulgacov, S., \& Costa, R. S. (2011). As pressões ambientais e os fatores motivadores na formação e atuação de redes: Estudo de caso da Rede Maringá Modamix. Revista Eletrônica de 
INFLUÊNCIA DE PRESSÕES AMBIENTAIS NA FORMAÇÃO DE REDES MEDIADAS PELOS SISTEMAS DE CONTROLE GERENCIAL EM INCUBADORAS DE EMPRESAS

Administração do Centro do PR, 1(1), 35-53.

Miller, P. (1991). Accounting innovation beyond the enterprise: problematizing investment decisions and programming economic growth in the UK in the 1960s. Accounting, Organizations and Society, 16(8), 733-762.

Murro, E. V. B., \& Beuren, I. M. (2016). Redes de atores na perícia contábil judicial: uma análise à luz da Teoria Ator-Rede. Revista Brasileira de Gestão de Negócios, 18(62), 633-657.

Nitzl, C., Roldan, J. L., \& Cepeda, G. (2016). Mediation analysis in partial least squares path modeling: Helping researchers discuss more sophisticated models. Industrial Management \& Data Systems, 116(9), 1849-1864.

Oliveira, A. S., \& Callado, A. A. C. (2018). Fatores contingenciais e o controle gerencial: Uma avaliação em organizações não governamentais (ongs) brasileiras. Advances in Scientific and Applied Accounting, 11(1), 092-109.

Oyadomari, J. C. T. (2008). Uso do sistema de controle gerencial e desempenho: um estudo em empresas brasileiras sob a ótica da VBR. Tese de Doutorado, Universidade de São Paulo (FEA/USP), São Paulo, SP, Brasil.

Oyadomari, J. C. T., Cardoso, R. L., Silva, B. O. T., \& Perez, G. (2010). Sistemas de controle gerencial: Estudo de caso comparativo em empresas inovadoras no Brasil. Revista Universo Contábil, 6(4), 2134.

Pak, N. A. H. C., Alwib, N. M., \& Ismailb, S. (2020). Translation of management control system in solid waste management network. Anais do Proceedings of the 4th UUM International Qualitative Research Conference, Virtual Conference, 2020.

Pipan, T., \& Czarniawska, B. (2010). How to construct an actor-network: Management accounting from idea to practice. Critical Perspectives on Accounting, 21(3), 243-251.

Pollack, J., Costello, K., \& Sankaran, S. (2013). Applying Actor-Network Theory as a sensemaking framework for complex organisational change programs. International Journal of Project Management, 31(8), 1118-1128.

Preston, A. M., Cooper, D. J., \& Coombs, R. W. (1992). Fabricating budgets: A study of the production of management budgeting in the National Health Service. Accounting, Organizations and Society, 17(6), 561-593.

Quattrone, P., \& Hopper, T. (2001). What does organizational change mean? Speculations on a taken for granted category. Management Accounting Research, 12(4), 403-435.

Quattrone, P., \& Hopper, T. (2005). A ‘time-space odyssey': Management control systems in two multinational organisations. Accounting, Organizations and Society, 30(7), 735-764.

Raupp, F. M., \& Beuren, I. M. (2006). O suporte das incubadoras brasileiras para potencializar as características empreendedoras nas empresas incubadas. Revista de Administração, 41(4), 419-430.

Rautiainen, A., \& Scapens, R. W. (2013). Path-dependencies, constrained transformations and dynamic agency: An accounting case study informed by both ANT and NIS. Qualitative Research in Accounting \& Management, 10(2), 100-126.

Ringle, C. M., Silva, D., \& Bido, D. S. (2014). Modelagem de equações estruturais com utilização do SmartPLS. REMark, 13(2), 54-73.

Rodger, K. J. (2007). Wildlife tourism and the natural sciences: Bringing them together. Doctoral dissertation, Murdoch University, Perth, Australia,

Silva, A., \& Beuren, I. B. (2020). Efeitos dos sistemas de controle gerencial e do compartilhamento de informações no risco interorganizacional de uma rede de franquia. Advances in Scientific \& Applied Accounting, 13(1), 03-22.

Simons, R. (1995). Levers of control. Cambridge: Harvard Business School Publishing.

Sobel, M. E. (1982) Asymptotic intervals for indirect effects in structural equations models. In: S. Leinhart (Ed.). Sociological methodology (p. 290-312). San Francisco: JosseyBass.

Speklé, R. F., Van Elten, H. J., \& Widener, S. K. (2017). Creativity and control: A paradox-evidence from the levers of control framework. Behavioral Research in Accounting, 29(2), 73-96.

Tonelli, D. F. (2016). Origens e afiliações epistemológicas da Teoria Ator-Rede: implicações para a análise organizacional. Cadernos EBAPE. BR, 14(2), 377-390.

Vieira, V. A. (2009). Moderação, mediação, moderadora-mediadora e efeitos indiretos em modelagem de equações estruturais: uma aplicação no modelo de desconfirmação de expectativas. RAUSP. Revista de Administração, 44(1), 17-33. 
Whittle, A., \& Mueller, F. (2010). Strategy, enrolment and accounting: The politics of strategic ideas. Accounting, Auditing \& Accountability Journal, 23(5), 626-646.

Widener, S. K. (2007). An empirical analysis of the levers of control framework. Accounting, Organizations and Society, 32(7), 757-788.

Windeck, D., Weber, J., \& Strauss, E. (2015). Enrolling managers to accept the business partner: The role of boundary objects. Journal of Management \& Governance, 19(3), 617-653.

Zawawi, N. H. M., \& Hoque, Z. (2020). Network control and balanced scorecard as inscriptions in purchaser-provider arrangements: Insights from a hybrid government agency. Accounting, Auditing \& Accountability Journal. ahead-of-print. Doi: https://doi.org/10.1108/AAAJ-11-2019-4242

\section{APÊNDICE A - QUESTIONÁRIO}

\section{Formação das redes de atores humanos e não-humanos}

1. Assinale o nível de importância das questões, relativas ao processo de formação de redes e busca de novos parceiros de negócios pela incubadora. Eescala: 1 (extremamente baixo) a 7 (extremamente alto).

Perfil e características comportamentais do empreendedor.

Perfil e características dos profissionais do suporte administrativo da incubadora.

Perfil e características dos profissionais do suporte financeiro da incubadora.

Perfil e características dos profissionais do suporte à estrutura organizacional da incubadora.

Bancos de fomento e financiamento.

Fundações de amparo à pesquisa.

Universidades.

Serviços de apoio à inovação e tecnologia para micro e pequenas empresas (ex: consultorias).

2. Assinale seu nível de concordância com as assertivas abaixo quanto aos procedimentos iniciais relevantes para a formação de redes e busca de novos parceiros de negócios pela incubadora. Escala: 1 (extremamente baixo) a 7 (extremamente alto).

A incubadora define com clareza o que espera das parcerias com bancos de fomento e financiamento. A incubadora define com clareza o que espera das parcerias com fundações de amparo à pesquisa.

A incubadora define com clareza o que espera das parcerias com universidades.

A incubadora define com clareza o que espera das parcerias com serviços de apoio à inovação e tecnologia para micro e pequenas empresas.

Os empreendedores incubados recebem orientações pertinentes para o desenvolvimento de suas atividades.

3. Assinale seu nível de concordância com as assertivas abaixo quanto aos relacionamentos necessários para a formação de redes e desenvolvimento de novas parceiras para incubadora e suas respetivas incubadas. Escala: 1 (extremamente baixo) a 7 (extremamente alto).

Um relacionamento próximo com os bancos de fomento permite suprir as necessidades das incubadas. Um relacionamento próximo com as fundações de amparo à pesquisa permite suprir as necessidades das incubadas.

Um relacionamento próximo com os serviços de apoio à inovação e tecnologia para micro e pequenas empresas permite suprir as necessidades das incubadas.

Um relacionamento próximo com as universidades permite suprir as necessidades das incubadas.

Os profissionais de suporte administrativo e financeiro das incubadoras buscam desenvolver relacionamentos com profissionais de outras áreas para o suporte às empresas incubadas.

4. Assinale seu nível de concordância com as assertivas abaixo quanto aos papéis de cada ator no processo de formação de redes e busca de novos parceiros de negócios. Escala: 1 (extremamente baixo) a 7 (extremamente alto).

Editais ou chamadas públicas de bancos de fomentos e financiamento auxiliam nas atividades desenvolvidas pela incubadora.

Editais ou chamadas públicas de fundações de amparo à pesquisa auxiliam nas atividades 
desenvolvidas pela incubadora.

Editais ou chamadas públicas de universidades auxiliam nas atividades desenvolvidas pela incubadora.

Editais ou chamadas públicas de serviços de apoio a inovação e tecnologia à micro e pequenas empresas auxiliam nas atividades desenvolvidas pela incubadora.

As orientações emitidas pela incubadora subsidiam os profissionais empreendedores desenvolverem suas atividades.

5. Assinale seu nível de concordância com as assertivas abaixo quanto à consolidação e estabilização das relações entre os elementos do processo de formação de redes e busca de novos parceiros de negócios. Escala: 1 (extremamente baixo) a 7 (extremamente alto).

A incubadora é um dos componentes principais na formação de redes entre incubadas e demais atores. A proximidade da incubadora com os bancos de fomento contribui para o desempenho das atividades das incubadas.

A proximidade da incubadora com as fundações de amparo à pesquisa contribui para o desempenho das atividades das incubadas.

A proximidade da incubadora com as universidades contribui para o desempenho das atividades das incubadas.

A proximidade das incubadoras com os serviços de apoio à inovação e tecnologia para micro e pequenas empresas contribui para o desempenho das atividades das incubadas.

Os relacionamentos da incubadora afetam a formação de redes dos profissionais empreendedores.

\section{Uso dos Sistemas de Controle Gerencial - Sistemas de Crenças e de Restrições}

6. Assinale seu grau de concordância, no contexto da incubadora, que cada assertiva contribui para o desenvolvimento de relacionamentos internos e interorganizacionais. Escala: 1 (Discordo totalmente) a 7 (Concordo totalmente).

A declaração de missão da incubadora comunica claramente os valores fundamentais para o desenvolvimento de relacionamentos internos e interorganizacionais.

Os gestores de topo comunicam os valores fundamentais da incubadora para o desenvolvimento de relacionamentos internos e interorganizacionais.

A força de trabalho da incubadora está ciente dos valores fundamentais para o desenvolvimento de relacionamentos internos e interorganizacionais.

A declaração de missão da incubadora inspira nossa força de trabalho a desenvolver relacionamentos internos e interorganizacionais.

A incubadora se baseia em um código de conduta para definir o comportamento apropriado no relacionamento interno entre a nossa força de trabalho e os relacionamentos interorganizacionais.

O código de conduta da incubadora informa a nossa força de trabalho sobre os comportamentos que estão fora dos limites nos relacionamentos internos e interorganizacionais.

A incubadora tem um sistema que comunica nossa força de trabalho dos riscos que devem ser evitados nos relacionamentos internos e interorganizacionais.

Nossa força de trabalho está ciente do código de conduta da incubadora no que concerne aos relacionamentos internos e interorganizacionais.

\section{Uso dos Sistemas de Controle Gerencial - Uso Diagnóstico e Interativo}

7. Indique a intensidade de uso do Sistema de Controle Gerencial e/ou Medidas Administrativas de Controle em âmbitos interno e externo da incubadora. Escala: 1 (Não existe na incubadora) a 7 (Muito usado de modo geral).

Acompanhar o progresso das atividades em direção às metas.

Monitorar os resultados.

Comparar os resultados com as expectativas.

Revisar as medidas chave de desempenho. 
Promover a discussão em reuniões entre superiores, subordinados e pares.

Proporcionar o contínuo desafio e discutir os dados subjacentes, os pressupostos e os planos de ação.

Fornecer uma visão comum da incubadora.

Oportunizar a incubadora concentrar-se em questões comuns.

Possibilitar a organização focalizar-se nos fatores críticos de sucesso.

Desenvolver um vocabulário comum na incubadora.

\section{Pressões Ambientais}

8. Nas assertivas abaixo aponte o grau de presença que cada condição ambiental é incorporada ao processo de formação de redes e busca de novos parceiros de negócios pela incubadora.

Escala: 1 (pouco presente) a 7 (muito presente).

Complexidade tecnológica disponível para inovação de novos processos de produção.

Dinamicidade e variação tecnológica com que os produtos se tornam obsoletos.

Variação do gosto e preferências dos clientes.

Organizações com capacidade de mudar os valores culturais.

Valores e normas que se alteram a medida que os eventos afetam a população envolvida.

Estratégias governamentais para proteger as atividades industriais.

Estratégias governamentais no que diz respeito aos seus investimentos.

Atitude do governo em relação aos investimentos estrangeiros.

Tipos de alianças com outros países.

Período inflacionário e aumento no nível de pressões.

Integração global do comércio e da livre concorrência.

Diminuição da demanda no mercado (interno e externo). 